\title{
Energy balance and obesity: a UK perspective on the gluttony $v$. sloth debate
}

\author{
D. Joe Millward* \\ Department of Nutrition and Metabolism, Faculty of Health and Medical Sciences, University of Surrey, Guildford GU2 7XH, UK
}

\section{Abstract}

Obesity in the UK was assumed to have developed against a population decline in physical activity, with health messages focused on diet and exercise prevention strategies. Doubly-labelled water (DLW) studies of energy expenditure have indicated the alternative scenario that the increased obesity prevalence reflects excessive food energy intake with physical activity levels unchanged. This analysis is questionable, deriving in part from a weakness of the DLW methodology in identifying changing physical activity levels within populations of increasing body weight. This has resulted in an underestimation of the reduction in physical activity in the overweight and obese, as revealed by direct studies of such behaviour. Furthermore, a close examination of food energy supply, household food purchases and individual food energy consumption since 1955, in relation to likely estimates of current intakes indicated by simple modelling of predicted energy expenditure, identifies: (a) food energy supply as markedly overestimating energy intakes; (b) individual food energy consumption as markedly underestimating energy intakes; and (c) household food purchase data as the closest match to predicted current food energy intakes. Energy intakes indicated by this latter method have fallen by between 20 to $30 \%$, suggesting comparable falls in physical activity. Although unequivocal evidence for a matching UK trend in falling physical activity is limited, as is evidence that obesity follows reductions in physical activity, such a link has been recently suggested in a large prospective study in adolescents. Thus, for the UK, obesity has developed within a 'move less-eat somewhat less but still too much' scenario. A focus on both diet and exercise should remain the appropriate public health policy.

Key words: Doubly-labelled water: Food energy intake: Energy expenditure: Physical activity

\section{Introduction}

Obesity is at the heart of all national discussions about public health and well-being, having reached epidemic proportions within the developed world and moving towards such levels within many parts of the developing world. A high BMI is now identified as the sixth most important risk factor for global death and disease burden, ranking first in Australasia, second in North America and third in Western Europe ${ }^{(1)}$. The most recent information for England ${ }^{(2)}$ indicates that in 2010, most of the population, $69 \%$ of men and $60 \%$ of women, were overweight (BMI $\geq 25$ and $<30 \mathrm{~kg} / \mathrm{m}^{2}$ ), with $26 \%$ obese (BMI $\geq 30 \mathrm{~kg} / \mathrm{m}^{2}$ ), almost twice the prevalence observed in 1993. This is a consequence of a steady increase in adult BMI which began in Britain during the $1950 \mathrm{~s}^{(3,4)}$ and which is well documented from $1980^{(5)}$ (see Fig. 1). Obesity was first recognised as a 'hazard to health' in the UK in $1976^{(3)}$, with the mean adult BMI reaching
$25 \mathrm{~kg} / \mathrm{m}^{2}$ in the early $1980 \mathrm{~s}$ for men and the late $1980 \mathrm{~s}$ for women ${ }^{(5)}$. The consequences of these changes for the health of the general population are now becoming clear $^{(6,7)}$, with all-cause mortality increasing by about $30 \%$ for each 5-unit increase in BMI above the reference minimum mortality range of $20 \cdot 0$ to $24.9 \mathrm{~kg} / \mathrm{m}^{2}$ up to a BMI value of $49.9 \mathrm{~kg} / \mathrm{m}^{2}$. These reports identify mechanisms linking excess adiposity, especially visceral adiposity, with vascular disease, the main cause of increased mortality, through hypertension, dyslipidaemia and inflammation. Even for the elderly, for whom there has been some debate about the potential hazard of being overweight $^{(8)}$ and for whom BMI may overestimate adiposity if height falls with age, it has been clearly shown that increased waist circumference increases risk of all-cause, cardiovascular (CVD) and cancer mortality ${ }^{(9)}$. Whilst detailed socio-economic models of its aetiology have been elaborated, and an extensive literature on the types and effectiveness of weight-reduction interventions for

\footnotetext{
Abbreviations: ALSPAC, Avon Longitudinal Study of Parents and Children; DIT, dietary induced thermogenesis; DLW, doubly-labelled water; DRI, dietary reference intake; DRV, dietary reference value; EE, energy expenditure; EFS, Expenditure and Food Survey; EI, energy intake; MET, metabolic equivalents of task; MVPA, moderate to vigorous physical activity; NDNS, National Diet and Nutrition Survey; NFS, National Food Survey; NHANES, National Health and Nutrition Examination Survey; PAEE, physical activity energy expenditure; PAL, physical activity level; Q, quartile; SPA, spontaneous physical activity; $\mathrm{TV}$, television; W, total body weight.
}

*Corresponding author: Dr D. J. Millward, email D.Millward@surrey.ac.uk 

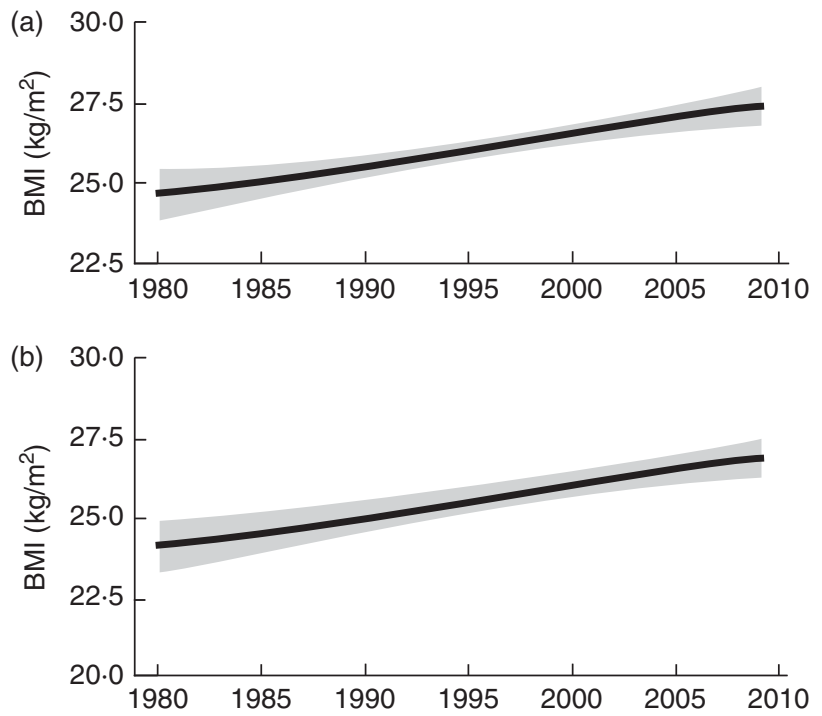

Fig. 1. Trends in BMI for UK males (a) and females (b) 1980-2010. The solid line represents the posterior mean and the shaded area the $95 \%$ uncertainty interval. (Redrawn from Finucane et al. ${ }^{(5)}$ ).

individuals and population groups has accumulated ${ }^{(10)}$, no consensus has yet emerged about effective, populationbased strategies, particularly whether such strategies should focus on energy intake (EI), energy expenditure (EE), or both ${ }^{(10)}$.

One important reason for this lack of consensus is the lack of robust, objective measures of dietary intake and physical activity and of behavioural and attitudinal measures in large populations ${ }^{\text {(10) }}$ which prevents the debate being informed by unequivocal data. Also the detailed time course of weight gain is largely undocumented, so that simple questions about whether weight gain is slow and incremental or episodic cannot be answered. However, it is also the case that the basic human biology and nutritional physiology of obesity at the level of energy balance and energy flux remain poorly understood and as a result controversial. Most would agree with the simple model frameworks proposed by Popkin ${ }^{(11)}$ or Bouchard $^{(12)}$ who view the energy imbalance, i.e. an excess of EI over EE, and weight gain to be as a result of large shifts in both diet and physical activity patterns. These shifts have occurred to a greater or lesser extent on a global basis, resulting from an obesogenic social and built environment to which populations, many of whom carry obesity-related genetic traits, are exposed to, and who exhibit obesogenic behaviour in terms of overconsumption and under-activity. In relation to the genetics of obesity, this is by no means straightforward. Notwithstanding the great advances in identifying obesity-related SNP that contribute to the clearly demonstrated heritability of obesity, i.e. an individual's risk of adult obesity increases by $2 \cdot 2$ - to $3 \cdot 2$-fold or by 5 - to 15 -fold if one or both parents were obese throughout childhood and adolescence ${ }^{(13)}$, such increased risk reflects both genetic as well as familial environmental susceptibility. Furthermore although genome-wide association studies, performed mainly in white European adults, have to date identified at least fifty-two loci robustly associated with obesity-related traits ${ }^{(13)}$, of which the best-known fat mass and obesity associated (FTO) risk allele occurs with a high frequency (46\%) in white Europeans, with each trait increasing BMI, by up to 0.33 BMI units in the case of the FTO variant ${ }^{(14)}$, the predictive ability of the BMI-associated loci remains poor. Thus these fifty-two currently identified traits account for a total of only $6-7 \%$ of the variance in BMI. Although genetic studies should reveal new insights into the biological pathways that underlie weight gain and body fat accumulation, and may eventually explain why humans are better able to defend against weight loss than against weight gain, to date progress in this direction appears to be slow. This has allowed a range of views and interpretations to develop, not only in relation to the more esoteric questions, such as the evolutionary origins of human susceptibility to obesogenic environments and diets ${ }^{(15,16)}$, but also over questions relating to basic issues such as the relative importance of increasing EI or decreasing EE as the primary driver of weight gain. One approach to the debate is to recognise that such debates are over-simplistic. For example, there is an obvious interaction between sedentary behaviour and food overconsumption ${ }^{(17)}$. In addition, elaborate very large-scale complex obesity system maps such as those described in the Foresight report have been produced that include all possible influences, interactions and potential solutions ${ }^{(10)}$, and which argue that 'disproportionate attention has been given to debates over the relative importance of diet or inactivity in the aetiology of obesity, given that the subtle shifts in energy balance which have occurred at a population level are below the limits of detection of current methodologies'. The other approach is to place one main driver of obesity, the food supply, at the centre of the problem $^{(18)}$. This automatically downscales all other influences. Rutter ${ }^{(19)}$ has commented that such simple energy balance questions assume that obesity has evolved within a complicated but ultimately knowable and predictable system and can therefore be modelled and understood. In his view obesity should be treated as the outcome of a complex system with understanding and solutions unlikely to come from the perspective of individual scientific specialisms, requiring instead 'big thinking, many changes ${ }^{, 20)}$. While this may well be true, it is nevertheless important to ensure that within the 'complicated system' discussion, the detailed arguments are logical and stand up to scrutiny. Although much of the recent debate has evolved in relation to the growth of obesity in the USA and elsewhere, the main focus here is on the development of obesity in the UK population. 


\section{Drivers of obesity: the current gluttony $v$. sloth debate}

In 1995, commenting on the doubling of obesity prevalence in Britain between 1980 and 1991, Prentice \& $\mathrm{Jebb}^{(21)}$ argued that although it was generally assumed that ready access to highly palatable foods induces excess consumption so that simple gluttony causes obesity, in fact, average recorded EI in Britain had declined substantially as obesity rates have escalated. The implication was that increasing sloth was also an important driver in that levels of physical activity, and hence energy needs, had declined even faster. Their interpretation of the evidence was that modern inactive lifestyles were at least as important as diet in the aetiology of obesity and possibly represent the dominant factor. The importance of an inactive lifestyle as well as an obesogenic diet was also identified by some US workers such as Hill and colleagues (Hill \& Peters ${ }^{(22)}$ ). In one review which examined the behavioural factors in the aetiology of obesity ${ }^{(23)}$, Hill made the important observation that the role of changes in EI was difficult to identify because weight gain itself increases EE, making it difficult to separate cause from effect in terms of EI and obesity. On the other hand, he reported evidence of reductions in physical activity in specific population groups. One example was the Amish community who chose not to adopt much of the technological change that has shaped physical activity behaviour in the wider population. On the basis of recorded walking activity of the Amish ${ }^{(24)}$ and Hill's and others' studies of average men and women, Hill identified a difference in daily $\mathrm{EE}$ of $400-600 \mathrm{kcal} / \mathrm{d} \quad(1670-2510 \mathrm{~kJ} / \mathrm{d})$ as an approximation of the reduction in physical activity that has occurred in the past decades. Reviewing links between obesity and physical activity in 1996, Ferro-Luzzi \& Martino ${ }^{(25)}$ concluded that at least for Western societies, the overall EE had fallen for some decades and lifestyles have become increasingly more sedentary. For example, one 7-year longitudinal study of self-reported physical activity in the late 1980 s and early 1990s in young US adults identified a $30 \%$ decrease in mean physical activity $^{(26)}$. The Ferro-Luzzi-Martino report followed from an analysis of time-budget surveys showing that both the time required for and energy spent on earning a living and domestic work had declined appreciably over recent decades, and that the associated expansion of free time involves considerable passive leisure.

A more recent analysis of the changes in occupation in the USA supports this view. Thus data on occupations in private industry from the US Bureau of Labor Statistics combined with National Health and Nutrition Examination Survey (NHANES) body weight changes show that the extent of the reduction in daily occupation-related EE $(>100 \mathrm{kcal} ;>420 \mathrm{~kJ})$ and associated estimated weight gain closely matches the observed weight gain between 1960 and 2003-2006 ${ }^{(27)}$. Clearly, such calculations are subject to a variety of assumptions but the authors remark that by not factoring in technological changes that reduce the extent of moderate-intensity occupations, they may have underestimated the fall in EE of the work force. Another likely example of a fall in EE being associated with an increase in obesity is the urbanisation of China. James ${ }^{(28)}$ estimates that the change from rural to modern urban life may involve a reduction of $400-800 \mathrm{kcal} / \mathrm{d}$ $(1670-3350 \mathrm{~kJ})$. Given this change and the associated dramatic increase in dietary energy density associated with increased sugar and a more than doubling in fat EI during this transition, the estimated current increase in adult weight of $0 \cdot 5-2 \mathrm{~kg} /$ year is, in his view, entirely predictable. One recent global study of emerging trends in decreased EE and increased sedentary patterns also identified a fall in activity ${ }^{(29)}$. This study examined both crosssectional and longitudinal datasets of physical activity in terms of metabolic equivalents of task (MET) for past and current activities across the four main physical activity fields over many decades and showed that MET values decreased in the USA, UK, China, Brazil and India over the time periods studied. These authors predict that physical inactivity and sedentary behaviours will continue to rise. However, as commented in another recent authoritative review of global physical activity level (PAL) ${ }^{(30)}$, the first in the Lancet's recent series on physical activity ${ }^{(31)}$, the collection and codification of data on PAL have been extremely difficult in the past because a standardised instrument suitable for international use has only been available since $2003^{(32)}$. Data collected over the last decade with this instrument indicate that for 122 countries a third of all adults and four-fifths of adolescents are reported not to reach public health guidelines for recommended levels of physical activity ${ }^{(30)}$. For children and adolescents, time budget analyses are much more difficult than for adults, but assessment of television (TV) watching has identified an increasing trend in some cases (for example, NHANES III in the $\mathrm{USA}^{(33)}$ and in Europe ${ }^{(34)}$ ) while others have found minimal change in either TV watching or vigorous physical activity as measured by self-administered questionnaires over the period 1985/ 1986 to $1997 / 1998^{(35)}$. One 5-year longitudinal study of physical activity and sedentary behaviour during adolescence reported substantial reductions in moderate to vigorous physical activity (MVPA), particularly among girls, and increasing leisure-time computer use in girls and boys ${ }^{(36)}$ A 2005 review of evidence on sedentariness, fitness and attitudes concluded that physical activity in clearly defined contexts, active transport, school physical education and organised sports was declining in many countries ${ }^{(37)}$. In a study involving two 10-year-separated cross-sectional cohorts of Czech adolescents in 2000 and 2010 the doubling in obesity was accompanied by an increase in total sedentary behaviour, especially in girls, and a switch from TV watching to computer games ${ }^{(38)}$.

For the UK population the recent UK dietary reference values (DRV) report ${ }^{(39)}$ comments that both the National 
Diet and Nutrition Survey (NDNS) and the Health Surveys of countries within the UK, which estimate physical activity as the proportion of the survey population who achieve the UK recommended level, consistently show that the majority of individuals do not meet these physical activity recommendations. Similarly, despite numerous public recommendations to promote physical activity in the USA, one study showed that over four decades from 1958 to 1998 amongst a health-conscious population of US elderly there were only very modest increases ${ }^{(40)}$. The problem with all such estimates based on self-reported physical activity questionnaires, including the International Physical Activity Questionnaire ${ }^{(32)}$, is that they are likely to overreport physical activity in the population and have limited accuracy in representing habitual levels. Physical activity as an aetiological factor is discussed further below.

A related and important theme of Hill's work is the magnitude of the mismatch between EI and EE responsible for the observed rates of weight gain. They introduced a statistic describing the 'energy gap', the required change in EE relative to EI necessary to restore energy balance, which in their terms was the same amount as the excess daily intake over expenditure calculated from weight gain over time. Thus on the basis of a deposited energy content of weight gain of $7.7 \mathrm{kcal} / \mathrm{g}(32.2 \mathrm{~kJ} / \mathrm{g})$ they identified that $1 \mathrm{lb}(0.45 \mathrm{~kg})$ of weight gain represented $3500 \mathrm{kcal}$ $(14640 \mathrm{~kJ})$ of body energy and estimated from the distribution of weight gain over an 8-year period indicated in NHANES that this was equivalent to daily energy imbalances for the median weight gain of only $15 \mathrm{kcal} / \mathrm{d}$ $(63 \mathrm{~kJ} / \mathrm{d})$, with $50 \mathrm{kcal} / \mathrm{d}(209 \mathrm{~kJ} / \mathrm{d})$ accounting for the 90th percentile ${ }^{(41)}$.

Although this calculation is simplistic and has been criticised $^{(42)}$ it is undeniably the case that on a daily basis, a very small energy imbalance between EI and EE can mediate weight gain. Such a response against a background of a declining EE became the mainstream view in the UK as indicated by the Foresight report ${ }^{(10)}$, i.e. 'It is generally accepted, at least for adults, that as society has changed, there have been systematic reductions in energy expenditure, as a consequence of fewer manual jobs, increases in car ownership and the rise of labour-saving devices for use at home and work. Despite evidence of reductions in walking and cycling to school, the impact of similar changes on physical activity in children is less clear. Other factors may also be relevant, such as the increased fears of parents about unsupervised outdoor play for chil-

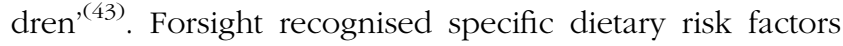
for obesity such as foods with a high energy density, diets high in fat and low in fibre, and the consumption of sugar-rich drinks, all compounded by large portion sizes $^{(44)}$ but importantly argued that 'disproportionate attention has been given to often sterile debates' about causality (poor diet or lack of exercise). The report argued that subtle shifts in both diet and physical activity that influence obesity trends may be below the limits of detection of current methodologies ${ }^{(44,45)}$.

This comment was most probably in response to an increasingly prominent view that rejected the Prentice \& Jebb position that sloth played a bigger part than gluttony and which placed sole responsibility on the food supply as the main driver of obesity. Cutler and colleagues, in addressing the question 'Why have Americans become more obese?' (Cutler et al. ${ }^{(46)}$ ) and subsequently 'Why is the developed world obese?' (Bleich et al. ${ }^{(47)}$ ) argued that for the USA and for most other developed countries 'calories expended' have not changed significantly since 1980, while 'calories consumed' have risen markedly so that rising obesity is primarily the result of consuming more 'calories'. They prefaced their discussion with some energy balance calculations which purport to show that the net energy imbalance required to account for observed weight gains (a 10- to $12-\mathrm{lb}$ (4.5- to $5 \cdot 4-\mathrm{kg}$ ) increase in median weight in two decades) is 'strikingly small' at about 100 to $150 \mathrm{kcal} / \mathrm{d}$ ( 420 to $630 \mathrm{~kJ} / \mathrm{d}$ ). In fact, the value they calculate is not an estimate of the likely daily energy imbalance but of the increase in EE and consequent EI (energy turnover or flux) at the end of the two decades when their 10 - to $12-\mathrm{lb}(4 \cdot 5-$ to $5 \cdot 4-\mathrm{kg})$ weight gain has occurred, i.e. the extra intake needed to support the energy demands of a larger individual. In fact, a weight change of $10 \mathrm{lb}(4.5 \mathrm{~kg})$ over 20 years is equivalent to less than $1 \mathrm{~g}$ weight gain/d requiring an unmeasurably small daily energy imbalance. This misplaced equality of the increase in energy turnover resulting from weight gain with the extent of daily energy imbalance to achieve such weight gain has become an important feature of the debate as discussed below.

Cutler et al. ${ }^{(46)}$ reviewed evidence on EI and conclude that in the USA between 1909 and 1950 urbanisation resulted in a decline in EE but obesity did not occur because EI also fell. However, they argue that EI increased from 1965 to 1999 by about $700 \mathrm{kcal}(2930 \mathrm{~kJ})(1978-1999)$ 'three to four times the increase needed to explain the increase in average obesity over the time period'. Furthermore, they argue that for EE voluntary exercise has not changed between 1965 and 1995, whilst the major reduction in occupational EE occurred between 1910 and 1970 with a much more modest change since, and with change in transportation to work having 'largely run its course by 1980'. They also argue that for children and the elderly for whom increases in obesity have occurred, reductions in employment-based $\mathrm{EE}$ cannot be used as the basis of a reduction in $\mathrm{EE}$ and, in the case of the elderly, they may be more active now than in 1980. They conclude that the most plausible explanation for the rise in obesity involves increased caloric intake, not reduced caloric expenditure'.

This view is repeated in a recent Lancet series ${ }^{(48)}$ in which Swinburn et al. ${ }^{(18)}$ echo Cutler's views and propose a scenario involving two distinct phases: 'the so-called 
move less, stay lean phase (1910-60), characterised by decreasing physical activity levels and energy intake, and a population that remained lean; and the subsequent socalled eat more, gain weight phase, characterised [after a "tipping point"] by increasing energy intake and a concomitant rise in population weight'. They argue that during these two phases two different mechanisms operate to achieve energy balance. In phase 1 , appetite mechanisms 'pull down energy intake, because intake was being matched to decreasing expenditure associated with decreases in physical activity so that obesity rates did not increase despite widespread uptake of mechanisation and motorisation'. In phase 2, weight gain restored energy balance by increasing energy expenditure (through increased RMR) to match increasing intake in response to increasingly available, cheap, tasty, highly promoted obesogenic foods. Clearly this view does not allow for weight gain to be driven by a positive energy balance consequent on reduced physical activity. On the contrary, the model is dependent on reduced activity before the tipping point driving a fall in EI.

The fact that what appear to be plausible analyses of the extent of change in physical activity in recent decades can reach such opposite conclusions compared with other commentators shows the difficulty in reaching a definite conclusion on this aspect of the debate.

\section{Direct measurements of energy expenditure}

While direct measurement of daily EE over 1-2 weeks with the doubly-labelled water (DLW) method has transformed our ability to study energy balance, to date, such data have yet to inform unambiguously on the gluttony $v$. sloth debate. Indeed, one of the first DLW reports on the obese showed that while BMR, total EE and physical activity energy expenditure (PAEE; $0.9 \times \mathrm{EE}-\mathrm{BMR}$ ) were all higher in obese compared with lean women, there was no difference in EE or PAEE calculated on a fat-free mass or total body weight (W) basis or in PAL $(\mathrm{EE} / \mathrm{BMR})^{(49)}$. Ferro-Luzzi \& Martino ${ }^{(25)}$ also showed that DLW-determined values of PAL were the same in lean third-world adults compared with overweight developedcountry subjects. These were surprising results at the time but have subsequently been confirmed repeatedly (and the implications of such data are further discussed below). DLW measurements of EE in terms of both EE and PAL were recently compared in two large cohorts of women from sociocultural environments that give rise to the extremes of obesity prevalence, rural Nigeria and African American women in Chicago, mean BMI $=23$ or $31 \mathrm{~kg} / \mathrm{m}^{2}$, respectively ${ }^{(50)}$. The mean and distributions of PAL values were the same for the two cohorts and in each case weight gain during the 3 years after the baseline DLW measurement was unrelated to activity EE adjusted for W. The most recent attempt to develop the debate is a meta-analysis of all published DLW studies of adults living in developing and industrialised countries between 1986 and 2008 with the objective of examining whether EE and PAL values are higher for individuals in developing countries $^{(51)}$. An analysis of mean study data from 183 cohorts of subjects showed that neither EE, adjusted for W and age, nor PAL differed significantly between developing and industrialised countries. They concluded that this 'calls into question the role of energy expenditure in the cause of obesity at the population level'. In terms of year of publication they also showed very little change over the time period. Thus, although within a meta-regression of all examined studies, EE fell marginally $(P=0.05)$ over the time period for men, there was no change in women and there was no change in PAL for men or women. The study mean PAL values for men and women aged $<65$ years from the industrialised countries are shown in Fig. 2. It is clear that year of publication explained very little of the variance $(1.6 \%$ for the combined data), so that the mean fall in PAL from 1.81 in 1986 to 1.72 in 2008 cannot be interpreted as hard evidence of a reduction in physical activity over the two decades when the data were published.

In fact, such meta-analyses are unlikely to reveal much about actual population trends in EE because the individual studies involve for the most part very small numbers (median and 90th centile $n$ for each individual study $=14.5$ and 71 ). With very few exceptions, subjects for these studies were not selected as representative of the general population and as a result the published data are extremely heterogeneous. Certainly neither W nor BMI changed significantly within these studies over the time frame examined (W and BMI explained $<1 \%$ of the variance) and overall in the meta-regression of all published studies referred to above the authors report that after accounting for age, weight, development status and year of publication, the residual heterogeneity in mean study PAL values was close to $90 \%$ for men and women.

Another widely quoted report suggesting no change in PAEE in recent decades is an analysis of DLW data by

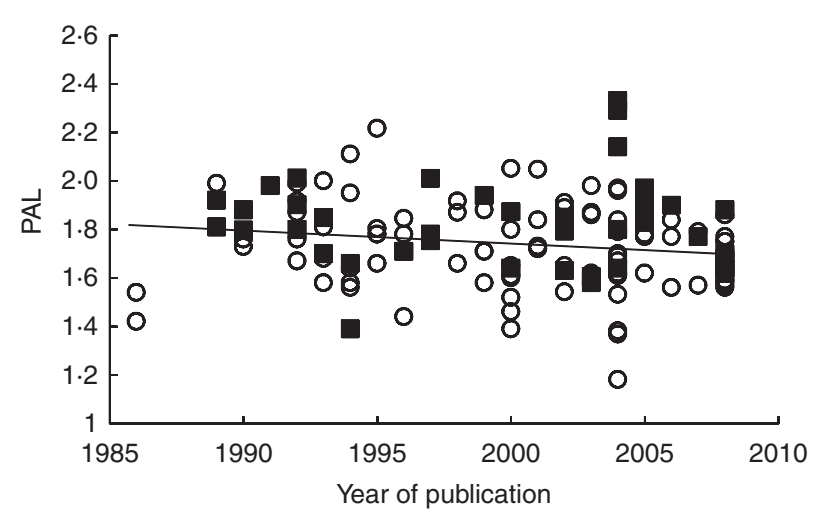

Fig. 2. Trends in doubly-labelled water-derived physical activity for published studies from industrialised countries. Mean physical activity level (PAL) values for men $(\square)$ and women $(O)$ aged $<65$ years from industrialised countries $\left(R^{2}\right.$ for the regression $\left.=0.016\right)$. (Data from Dugas et al. $\left.{ }^{(51)}\right)$. 
Westerterp \& Speakman ${ }^{(52)}$. This conclusion is based on an analysis of a small dataset of DLW studies of EE of men and women measured at Maastricht ( $n 366$ in nine separate groups starting in 1988). Trends in PAEE calculated in several, essentially similar, ways are interpreted as indicating either no change with time or, if anything, a slight increase. In fact the dataset is not large enough to draw any conclusions about time trends, with mean annual values exhibiting very considerable year-on-year changes and with the largest and the smallest mean annual values occurring in the first and second year. The fact that year of study was not an influence on EE, with W explaining 32\% of its variance, is not at all surprising given that the BMR component of EE varies directly with $\mathrm{W}$, as does all weight-bearing PAEE. They also report an increase with time in EE measured in US subjects but the results for this analysis are not shown, so that it is difficult to comment on. They also argue that the PAEE matches EE of wild animals. In fact the similarity between observed EE in Maastricht and that predicted on the basis of W according to a regression of $\mathrm{EE}$ on $\mathrm{W}$ in wild animals is also not helpful given that the $95 \%$ CI values of their derived prediction equation ranged from EE values equivalent to PAL values from 1 to $>2$ and with wild animal values at similar body weights exhibiting PAL values ranging from 1 to $2 \cdot 5$.

This same laboratory has published another DLW study given the title 'Physically active lifestyle does not decrease the risk of fattening, ${ }^{(53)}$. This study reports PAL values and fat gain in Dutch men and women over 10 years with a principal finding that 'a high initial activity level was predictive for a higher fat gain'. However, the data actually reported are an increase in body fat and BMI and a small average fall in PAL, with the most physically active subjects showing the largest reduction, so that individual changes in PAL and fat exhibited an inverse relationship; i.e. the subjects who reduced PAL the most, gained most fat and vice versa. Thus, a quite legitimate alternative title would be 'Reducing a physically active lifestyle increases the risk of fattening'.

The most widely quoted report that discusses obesity as a consequence of increased EI rather than reduced PAEE is that of Swinburn et $a l .^{(54)}$. This is an analysis of the relationship between W and 'energy flux', defined as $\mathrm{EE} \equiv \mathrm{EI}$, with EE measured by DLW, in a large cohort of adults with W ranging from 34 to $150 \mathrm{~kg}$ derived from eight published studies. The analysis is performed to identify the magnitude of what they define as 'the energy flux gap', the difference in EE between two time points defining the change from normal weight to obesity (in fact the same measure calculated by Cutler et al. ${ }^{(46)}$ discussed above). This 'energy flux gap' is distinct from the 'energy imbalance gap', i.e. the excess of EI over EE which results in weight gain, which, as discussed above is very small and not measurable. This is an important authoritative report in so far as the authors of the article (and of the response to criticism of the arguments made in the report ${ }^{(55,56)}$ ) include established leaders of the field of energy balance studies. Thus what they say cannot be lightly dismissed. However, the present author has questioned its main arguments ${ }^{(55)}$. The authors make two important points.

The first is that identifying the magnitude of the 'energy flux gap', the extra food EI required to maintain the increased body weight of an obese compared with a lean adult, is important because it quantifies the magnitude of the public health challenge in relation to the extent to which food intake needs to fall to reverse obesity. Clearly, any improved understanding of the energetics of obesity is to be welcomed. However, in the same way that weight gain develops gradually over time as a result of continued small positive energy balance, health care practitioners know that effective weight management programmes must involve modest and sustained EI reductions if they are likely to succeed. Thus it remains to be seen how knowledge of the 'energy flux gap' will help in terms of individual weight management programmes or in relation to advice to the food industry.

Secondly, and more importantly, the report is important in the context of the gluttony $v$. sloth debate. This is because of the way the authors interpret the increasing 'energy flux' (EE $\equiv \mathrm{EI}$ ) with increasing W which they demonstrate for their dataset and from which they derive a linear equation, $\mathrm{EE} \propto \mathrm{W}$, and the log-transformed version of the reverse of this, $\ln W \propto \ln$ total EI. They argue that the positive relationship of the latter equation implies causality, i.e. weight gain is driven by increasing EI. Swinburn et al. argue ${ }^{(54)}$ that the constraints of the first law of thermodynamics allowed us to infer that a high EI must be the major driver of higher body weight in modern populations. If obesity was primarily determined by lower PA (including higher sedentariness), one would expect that the consequent reductions in activity energy expenditure would result in a lower EE (EnFlux) being related to higher body weight (i.e. a negative relation). The fact that the observed relation was strongly positive implies that the high EnFlux associated with a high body weight is because a high EI is the main driver of both factors'. Is this a logical conclusion and is the observation itself in any way remarkable? In fact, as indicated above, the early DLW study of lean and obese subjects by Prentice et al. ${ }^{(49)}$ demonstrated such a relationship in that EE was higher in heavier obese women compared with lean because both BMR and PAEE were higher, with no difference after correcting for body weight. Thus, the relationship shown by Swinburn et al. is hardly surprising. In fact, using the terminology of an 'energy flux gap', this earlier study showed that the energy flux gap of women with a BMI of $32.9 \mathrm{~kg} / \mathrm{m}^{2}$ compared with $22 \cdot 1 \mathrm{~kg} / \mathrm{m}^{2}$ was $2 \cdot 23 \mathrm{MJ} / \mathrm{d}$.

The relationship between $\mathrm{EE}$ and $\mathrm{W}$ is examined in Fig. 3. The simple regression of $\mathrm{EE}$ on $\mathrm{W}$ for men and women reported by Swinburn et al. ${ }^{(54)}$ has been used to generate EE values at increasing body weights covering 


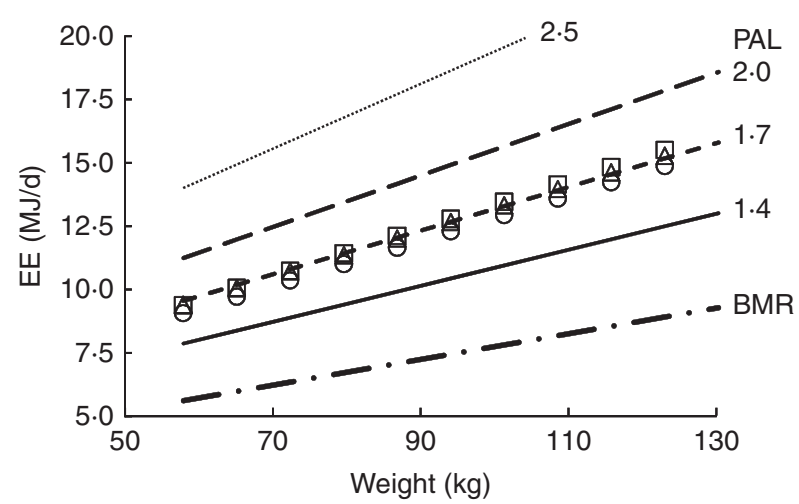

Fig. 3. Changes in total energy expenditure (EE) as a function of weight. Values shown are either calculated from BMR and physical activity level $(P A L)(E E=P A L \times B M R)$ or predicted from linear regressions of doublylabelled water-derived values for $\mathrm{EE}$ on weight for datasets reported by Swinburn et al. ${ }^{(54)}(\square)$, the UK dietary reference values report ${ }^{(39)}(\bigcirc)$ or the Institute of Medicine's dietary reference intake report ${ }^{(57)}(\triangle)$. The BMR values are calculated as the mean values for men and women calculated at weights equivalent to BMI values from 20 to $45 \mathrm{~kg} / \mathrm{m}^{2}$ at current heights of UK men and women with the Henry prediction equations for men and women aged $30-60$ years $^{(60)}$.

the within-population range of $\mathrm{W}$ in their dataset (equivalent to BMI values from 20 to $45 \mathrm{~kg} / \mathrm{m}^{2}$ with values expressed as the mean for men and women at their current average UK population heights). These values are compared with values calculated in a similar way from two other datasets using a similar linear regression of EE on W calculated by the present author. One is the DLW database published as part of the US Institute of Medicine's review of energy requirements ${ }^{(57)}$ that was compiled from individual values from a large number of generally small studies, many of which are included in the Swinburn dataset. The other is a large DLW dataset of urban American adults ( $n$ 890), which derives from two recent separate population-based studies ${ }^{(58,59)}$ compiled within the recent UK report on DRV for energy ${ }^{(39)}$. It is clear that the three DLW datasets show quite similar EE-body weight relationships. This is important, because the UK DRV dataset derives only from relatively recent population surveys so that the increasing weight relates to the current weight distribution within the population rather than representing a historical trend. The slope of any $\mathrm{EE}-\mathrm{W}$ relationship reflects the increasing BMR with $\mathrm{W}$, which is fixed and well studied (and shown in Fig. $3^{(60)}$ as mean values for middle-aged men and women ${ }^{(51)}$ ), and the way that PAEE varies with $\mathrm{W}$ within the study population, which is a variable. For $\mathrm{BMR} \propto \mathrm{W}$ the line shown is $\mathrm{EE}=0.0507 \times \mathrm{W}+2.69 \mathrm{MJ} / \mathrm{d}$. This equation is very similar to the regression of BMR on weight for all adults in both the dietary reference intake (DRI) and UK DRV datasets (slopes $=0.0517,0.0529$, intercepts $2.53,2.50$, respectively). The slopes and intercepts of the lines at fixed PAL values increase directly with the PAL values shown in Fig. $3(1.4,1 \cdot 7,2 \cdot 0$ and $2 \cdot 5)$. By comparing the slopes and heights for the three population datasets with the fixed PAL plots as shown it is immediately apparent that all three datasets are very similar to each other and to a fixed PAL-W relationship of about $1 \cdot 7$. For the UK DRV dataset, the mean value of PAL was $1 \cdot 66$, which was independent of weight ${ }^{(39)}$. The two other datasets are very similar and indicate PAL values that increase very slightly from just below 1.7 to just above 1.7 over the weight ranges indicated. This is consistent with actual reported PAL values for the DRI dataset of 1.70 at $50 \mathrm{~kg}$ rising to 1.72 at $140 \mathrm{~kg}^{(57)}$. Thus the $\mathrm{EE}-\mathrm{W}$ regression derived from the dataset examined by Swinburn et al. ${ }^{(54)}$ approximates to a population in which the mean PAL value is about 1.7 and more or less constant over the weight range of the population, with the positive slope driven by the increasing BMR with increasing W.

Is it likely that over such a wide range in weight the slope could be flat or negative as implied by the authors if PAL had declined? In fact, inspection of Fig. 3 shows that over the weight range indicated the slope would still be positive even if there was a systematic fall in PAL with increasing $\mathrm{W}$, as indicated for example by a line connecting a PAL of 2.0 at the lowest body weight with a PAL of 1.4 at the highest body weight, although the positive slope would be much shallower than that of the three population datasets. Indeed, in order for the slope to be obviously negative for this very wide range of body weights it would require a PAL value at or above 2.5 for the smallest values of $\mathrm{W}$, an unrealistically high sustainable rate of $\mathrm{EE}$, falling systematically to 1.4 at the highest value of $\mathrm{W}$, which is lower than the mean PAL observed for obese adults in current populations as discussed below. Thus for any dataset of values of $\mathrm{EE}$ and $\mathrm{W}$ in which $\mathrm{W}$ varies over such a wide range ( $\geq 60 \mathrm{~kg}$ ) as that shown in Fig. 3, because the increasing BMR with weight will always drive an increasing $\mathrm{EE}$ with $\mathrm{W}$ regardless of how PAL values change (at least within a range which is a physiologically reasonable for very small and very large individuals), a positive slope is entirely predictable and a negative slope is highly unlikely. It should be noted, however, that this is not true for smaller weight changes. Inspection of Fig. 3 shows that it is perfectly possible for a smaller weight change (for example, $\mathrm{W}$ increasing from 70 to $90 \mathrm{~kg}$ ) associated with a reduction in PAL (for example, from 2 to 1.7 ) to result in EE-W relationships with a negative slope. However, such a relationship could not be extended to include body weights markedly outside the limited range. What this means is that any examination of population data which includes the range of body weights shown in Fig. 3 will result in a EE-W relationship, the physiological causality of which is that increasing W drives increasing BMR and EE. To interpret EE as energy flux and therefore EI does not change this causality. Furthermore, it also follows that datasets which include very wide body weight ranges are quite unsuitable for deriving $\mathrm{EE} \propto \mathrm{W}$ relationships which can usefully be used to predict relatively small population-based weight changes from changes in EI as discussed below. 
The next question relates to whether anything can be inferred from the relationships shown in Fig. 3, about the mechanism of increasing $\mathrm{W}$, whether it is described in terms of energy flux or EI as opposed to EE as measured. Does it help the debate as to whether the positive energy balance driving weight gain results from gluttony (an increase in EI) or sloth (a fall in PAEE and EE)? In response to a criticism that the W-EE relationship offers no insight into the causality of weight gain ${ }^{(55)}$, they respond ${ }^{(56)}$ : 'We agree that, although population weight gains could theoretically be due to a drop in physical activity energy expenditure (PAEE), this would need to be so large and uniform as to be physiologically unlikely.' They also argue: 'Conceptualizing how a reduction in PAEE could act as a driver toward a state of higher mean EE that accompanies the higher weight is a conundrum, so postulating an increase in EI as the major driver of higher body weight in modern populations seems far more parsimonious and physiologic.' The logic of the first of these statements is difficult to identify given that the very small but sustained daily positive energy balance required for weight gain can occur through either an increase in EI or a fall in EE. The second statement is simply an opinion unsupported by argument.

Further insight into the arguments presented by Swinburn et $a l .{ }^{(54)}$ is indicated by subsequent applications of their $\ln \mathrm{W} \propto \ln \mathrm{l}$ I relationship (the log-transformed reverse of the EI $\propto$ W relationship shown in Fig. 3), in an attempt to identify the mechanism of weight gain with one study involving the $\mathrm{UK}^{(61)}$. This study is quoted in their Lancet paper (Swinburn et $a l^{(18)}$ ) as one of 'several studies [which] have tested the hypothesis that increases in the food supply are the dominant drivers of the weight gain in populations ... and ... more than sufficient to explain ... most of the weight increase in the UK since the 1980s'. In this study the authors examine the actual weight gain reported by NDNS surveys in the UK between 1986 and 2000 and compare this with predicted weight gains. This prediction is made with their inverted log-transformed regression $(\ln W \propto \operatorname{lnEI})$ and food EI measured over this period. They identify a number of different measures of food EI and choose values indicating an increase (FAO food balance sheet data indicating food supply at a national level adjusted for wastage). They predict weights from the EI, showing them to be lower than observed weights (by about $20 \%$ for men and $40 \%$ for women). However, they focus on the calculated weight gains that are lower than observed values for men $(4.7 v .7 .7 \mathrm{~kg}$ ) but slightly higher than observed values for women $(6.43 v .5 .4 \mathrm{~kg})$. They conclude that in men the lower than predicted weight gain shows that weight gain was due to both increased EI and decreased physical activity. However, for women they argue that 'an increase in total energy intake was sufficient to explain the increase in body weight over this time period'. In another similar study they undertake the same calculations of weight changes from changes in EI in the US population and come to the same conclusion that increased food energy supply is more than sufficient to explain the US epidemic of obesity ${ }^{(62)}$. Is it sensible to assume that it is possible to identify the aetiology of weight gain in terms of gluttony or sloth from calculations such as these?

The authors argue ${ }^{(62)}$... the relation between energy flux and body weight ... is assumed to apply to the US population over the time period studied. The multicountry data used to generate those equations suggests that this positive relation between energy flux and body weight is applicable across populations.' In fact, as shown in Fig. 3, their equation describes the $\mathrm{EE}-\mathrm{W}$ relationship for adults of increasing $\mathrm{W}$ with a more or less constant level of physical activity (PAL about 1.7) and will only accurately predict W from EI for such a population group. Because with their equation the recorded EI values predict much lower than observed body weights, especially for the women, either the equation is inappropriate (i.e. actual PAL values are $<1 \cdot 7$, especially for women, and vary between 1986 and 2000), or the EI values are underestimates of true food intakes. Either of these explanations could be true and cannot be discriminated between, so that the exercise itself seems of dubious value.

Secondly, and crucially, these authors were only able to develop their arguments by their choice of EI data which increased between 1986 and 2000. As they discuss, EI recorded by the NDNS or by the National Food Survey (NFS) fell over this time period, so their equation would have predicted a fall in body weight and the weight gain would only be explainable in terms of an even greater fall in physical activity. Clearly, as they argue, measurement of food intake by the various methods available is fraught with difficulty and their criticisms of both the NDNS and NFS are valid but few would invest the FAO food supply data with sufficient accuracy to warrant the sort of exercise described by these authors even if the methodology were sound.

There is a place for very simple modelling of likely changes in EE/EI as a function of change in weight and lifestyle to test the likely accuracy of reported levels of UK food intakes. This is discussed further below. However, it is arguable that DLW measurements of EE are unlikely in themselves to answer the key gluttony $v$. sloth question about causality for two reasons. One is the problem posed by weight change in interpreting changes in DLW-derived PAEE and this is discussed below. The other is that, because the very small positive energy balance required to initiate weight gain can occur through any combination of changes in EI or EE which results in $\mathrm{EI}>\mathrm{EE}$, a DLW measurements of EE is unlikely to indicate which of these changes has occurred. The DLW measurement indicates the amount of EI required to balance EE during weight stability, i.e. the mean EE for a short time period (usually 2 weeks) and is not a true measure of EI during the measurement period (or at any other time). 
It is only a proxy for habitual EI if two caveats are observed: (1) subjects are in energy balance during the measurement period; and (2) physical activity behaviour during the measurement period is the same as habitual behaviour. For the first of these caveats, only precise measurement of weight and/or body composition change or EI over the period would inform on whether EI differed from EE (if such measurements were possible). Because subjects may be advised to maintain stable weight, or may do this consciously or unconsciously by changing EI, during the DLW measurement period EI may differ from habitual EI. As for the second caveat, EE is known to vary over time because behaviour is not constant. Within-subject repeated measurement of EE by DLW showed a CV of $12.6 \%{ }^{(50)}$, with some individuals exhibiting $\mathrm{EE}$ in the second measurement of only $50 \%$ of the first, albeit with at least 1 year between measurements.

\section{Body weight influence on physical activity energy} expenditure and physical activity behaviour

A surprising feature about the DLW database is that there is no evidence of a fall in PAL with increasing obesity, up to quite high levels. This is the case for both the US DRI dataset ${ }^{(57)}$ and that used to define the UK DRV ${ }^{(39,58,59)}$. The distribution of PAL values according to quartile (Q) of BMI within the latter dataset is shown in Table 1 . PAL values for Q4 (mean BMI: women, $33 \cdot 1 \mathrm{~kg} / \mathrm{m}^{2}$; men, $32 \cdot 2 \mathrm{~kg} / \mathrm{m}^{2}$ ), range from 1.28 to $2 \cdot 15 \mathrm{~kg} / \mathrm{m}^{2}$ with a median value of $1.63 \mathrm{~kg} / \mathrm{m}^{2}$ similar to that of BMI Q1 (mean BMI: women, $21.4 \mathrm{~kg} / \mathrm{m}^{2}$, men, $22 \cdot 9 \mathrm{~kg} / \mathrm{m}^{2}$ ). Similarly, in a small group of Dutch adults $(n 40 ; \mathrm{BMI}=24.3$ (range $19-31) \mathrm{kg} / \mathrm{m}^{2}$ ) there was no relationship between PAL and $\mathrm{BMI}^{(53)}$. This is contrary to the common perception of increasing sloth amongst the obese. Although this indeed appears a conundrum, DLW-measured PAL values are in fact seriously limited as predictors of actual physical activity behaviour. This is because of two potential difficulties. The first is what PAL represents and whether it can or should be corrected for body weight. The second is how it relates to actual behavioural changes when $\mathrm{W}$ is changing.

What does physical activity level represent and should it be corrected for body weight?

In the factorial model in which $\mathrm{EE}$ is expressed as $\mathrm{PAL} \times \mathrm{BMR}$, it has been implicit that the BMR component captures the weight, age and sex dependence of EE, with PAL a measure of PAEE independent of these variables. However, the relationship between PAL, PAEE and body weight is quite complex for a number of reasons. Some of the complexity is mathematical relating to PAL as a ratio (EE:BMR) and PAEE as an absolute value. In this case, of minor importance is the fact that because PAL describes all EE above the BMR, its physiological relationship with PAEE is not exact because of the inclusion of thermogenesis within PAL but not in PAEE. Dietary induced thermogenesis (DIT) is the main component of thermogenesis and is often assumed to be $10 \% \mathrm{EI}$, i.e. 10\% EE at energy balance. Thus PAEE can be adjusted for DIT as PAEE $=0.9 \times \mathrm{EE}-\mathrm{BMR}$. At low PAL values $(\mathrm{PAL} \leq 1.4)$, DIT accounts for about $50 \%$ of PAL (i.e. the extra EE above BMR), falling to $\leq 25 \%$ at high PAL values $(\geq 2 \cdot 0)$. This means that PAL increases less steeply than absolute PAEE and this effect becomes more marked with increasing size. Furthermore, and independent of this effect of DIT, PAL as a measure of absolute PAEE is not independent of W. This is because the PAEE represented by a PAL value will increase with $\mathrm{W}$ or conversely the effect of a fixed amount of PAEE on PAL gets smaller as size increases. The reason is that the increase in BMR with size contributes to both the numerator and denominator in the PAL calculation but PAEE contributes only to the numerator. In other words, to maintain a constant PAL with increasing size, PAEE would need to increase in proportion to the BMR. This effect is not large but does explain why for the population group shown in Table 1, the modest (but significant) increase in PAEE with BMI group

Table 1. Physical activity values of adult men and women according to BMl ${ }^{\star}$

\begin{tabular}{|c|c|c|c|c|c|c|c|c|c|}
\hline Sex & $n$ & BMI quartile & $\begin{array}{l}\text { Median BMI } \\
\left(\mathrm{kg} / \mathrm{m}^{2}\right)\end{array}$ & Minimum PAL† & Maximum PAL & Median PAL & $\begin{array}{l}\text { Median } \\
\text { PAEE } \\
(\mathrm{MJ})\end{array}$ & $\begin{array}{c}\text { Median } \\
\text { PAEE/BMI } \\
\left(\mathrm{kJ} \text { per } \mathrm{kg} / \mathrm{m}^{2}\right)\end{array}$ & $\begin{array}{c}\text { PAEE/BMI }{ }^{0.5} \\
\left(\mathrm{~kJ} \text { per }\left(\mathrm{kg} / \mathrm{m}^{2}\right)^{0.5}\right)\end{array}$ \\
\hline Female & 104 & 1 & 21.4 & $1 \cdot 27$ & $2 \cdot 26$ & 1.60 & 2.47 & 115 & 531 \\
\hline Female & 100 & 2 & $24 \cdot 4$ & $1 \cdot 33$ & 2.50 & 1.60 & 2.51 & 103 & 510 \\
\hline Female & 111 & 3 & $27 \cdot 3$ & $1 \cdot 29$ & $2 \cdot 34$ & 1.63 & 2.75 & 99 & 526 \\
\hline \multirow[t]{2}{*}{ Female } & 109 & 4 & $33 \cdot 1$ & $1 \cdot 28$ & $2 \cdot 15$ & 1.63 & 2.92 & 86 & 506 \\
\hline & & Q4/Q1 & & & & 1.02 & $1 \cdot 18$ & 0.75 & 0.95 \\
\hline Male & 114 & 1 & $22 \cdot 9$ & 1.29 & $2 \cdot 34$ & 1.66 & $3 \cdot 36$ & 145 & 702 \\
\hline Male & 117 & 2 & $25 \cdot 4$ & $1 \cdot 29$ & $2 \cdot 25$ & 1.65 & $3 \cdot 23$ & 127 & 639 \\
\hline Male & 117 & 3 & $28 \cdot 3$ & $1 \cdot 30$ & $2 \cdot 31$ & 1.65 & $3 \cdot 36$ & 119 & 631 \\
\hline \multirow[t]{2}{*}{ Male } & 118 & 4 & $32 \cdot 2$ & $1 \cdot 29$ & $2 \cdot 37$ & 1.62 & $3 \cdot 76$ & 115 & 660 \\
\hline & & Q4/Q1 & & & & 0.98 & $1 \cdot 12$ & 0.79 & 0.94 \\
\hline
\end{tabular}

PAL, physical activity level; PAEE, physical activity energy expenditure; Q, quartile; DLW, doubly-labelled water; EE, energy expenditure.

* Data from the combined DLW adult dataset compiled by the Scientific Advisory Committee on Nutrition ${ }^{(39)}$ from Tooze et al. ${ }^{(58)}$ and Moshfegh et al. ${ }^{(59)}$.

†PAL $=$ EE/BMR.

$\ddagger P A E E=0.9 \times E E-B M R$ 
$(\mathrm{Q} 4 / \mathrm{Q} 1=+12$ to $18 \%)$ is not observed for $\mathrm{PAL}$ $(\mathrm{Q} 4 / \mathrm{Q} 1=-2$ to $+2 \%)$.

A second complexity in the PAL-PAEE relationship is physiological. Clearly, size does influence absolute strength and the consequent ease of strength-requiring tasks as well as the energy cost of weight-bearing activities. It was shown some years ago that the PAL value associated with a fixed programme of work does increase with $\mathrm{W}^{(63)}$. This means that any discussion of relative PAL of the obese compared with lean populations needs to consider a correction for size. In fact, first-principle considerations indicate that the relationship of PAEE with $\mathrm{W}$ is complex. It is a function of both the proportion of PAEE that is weight-bearing such as stair climbing (which varies directly with W), as opposed to weight-independent activities such as cycling (with a minimal dependency on W). It also depends on the extent to which changes in $\mathrm{W}$ that influence body composition and shape influence the mechanical efficiency of external work done. A variable component of PAEE is spontaneous physical activity (SPA; fidgeting and miscellaneous non-planned activity), which can be substantial (for example, $100-800 \mathrm{kcal} / \mathrm{d}$ $(420-3350 \mathrm{~kJ})^{(64)}$ or $>30 \%$ of $\left.\mathrm{EE}^{(65)}\right)$. Because the extent of SPA is an individual behavioural phenotype ${ }^{(66)}$, with low levels predisposing to obesity, the possibility of a reducing SPA with increasing size is another complicating factor in relation to correcting PAEE for size. In fact, it has been argued that it may not be possible to adjust PAEE for size with any confidence and that great caution must be exercised when attempting to do so ${ }^{(67)}$. In 12-year-old girls the energy cost of walking at fixed speeds increased with body weight, especially at higher walking speeds ${ }^{(68)}$. In these latter studies MET values (EE/RMR) for walking at a $10 \%$ incline at $4.8 \mathrm{mph}$ for girls of $50 \mathrm{~kg}$ was about $40 \%$ higher than girls of $30 \mathrm{~kg}$, an increase which is obviously less than the $66.6 \%$ difference that would have occurred if the MET values were simply corrected by weight. In Table 1 after a simple adjustment of PAEE for size assuming all PAEE is weight bearing, i.e. PAEE/BMI, PAEE falls with increasing size by $25 \%$ in women and $21 \%$ in men (Q1 to Q4). However, if PAEE represents a mix of activities so that the appropriate exponent of BMI is $0.5^{(49)}$, the fall in PAEE is much less. This means that in the population, PAEE may fall with increasing obesity but the extent is difficult to identify. However, inspection of Fig. 4, showing PAEE for an adult urban population corrected for size assuming it is all weight bearing (i.e. PAEE/BMI), indicates that with increasing BMI in both men and women there is still a very wide range of PAEE/BMI values within the overweight and obese range up to BMI values of $40 \mathrm{~kg} / \mathrm{m}^{2}$, with BMI explaining only $4-7 \%$ of the variance. In fact, the apparent decline in PAEE with increasing BMI is still less than might be expected, i.e. a fall of about $50 \%$ over a BMI range from 18 to $50 \mathrm{~kg} / \mathrm{m}^{2}$. This raises the second major problem in interpreting DLW measures of physical

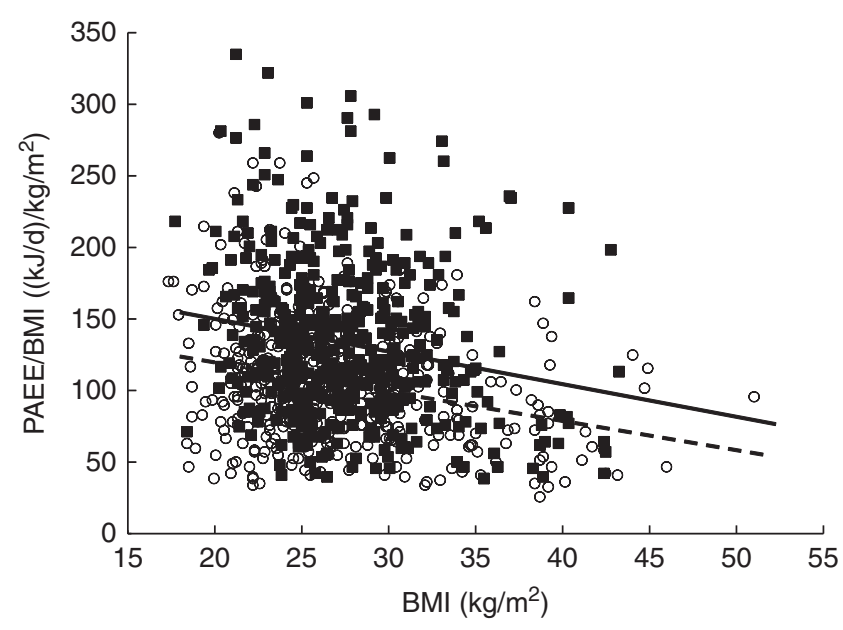

Fig. 4. Physical activity energy expenditure (PAEE) for an adult urban population corrected for body weight as a function of increasing size. Linear regressions shown are for men $\left(\square,-, r^{2}-0.040, P \leq 0.0001\right)$ and women $\left(\mathrm{O},---, r^{2} 0.066, P \leq 0.0001\right)$, and indicate that over a $\mathrm{BMI}$ range from 18 to $50 \mathrm{~kg} / \mathrm{m}^{2}$ PAEE corrected for size falls on average by $50 \%$ for men and women. PAEE $(0.9 \times$ total energy expenditure $-\mathrm{BMR})$ is corrected for body weight (BMI) assuming it is all weight bearing. (Dataset compiled in Scientific Advisory Committee on Nutrition ${ }^{(39)}$ from Tooze et al. ${ }^{(58)}$ and Moshfegh et al. $\left.{ }^{(59)}\right)$.

activity in terms of PAL or PAEE values: their ability to quantify physical activity changes in terms of behaviour.

How is physical activity level related to actual behavioural changes when body weight is changing?

PAEE behaviour can be measured by accelerometry with devices that assess movement in several spatial directions and there is a literature which clearly shows a mismatch between such measurements and EE per se. For example, Table 2 shows the results reported in a comprehensive study of lean (BMI $22 \mathrm{~kg} / \mathrm{m}^{2}$ ) and obese (BMI $36 \mathrm{~kg} / \mathrm{m}^{2}$ ) 18 -year-old adolescent boys and girls ${ }^{(69)}$, in which PAEE was calculated from DLW measurements of EE and by accelerometry. Physical activity measured with the accelerometer and uncorrected for body weight was lower in obese adolescents (by $24 \%$ in boys and $37 \%$ in girls) than in the age-, sex- and education-matched control lean subjects, whereas PAEE did not differ significantly between the groups and PAL values were only 6-8\% lower. In fact, when the accelerometry counts are expressed in relation to DLW-derived PAEE (the energetic intensity of the movement, counts/MJ of PAEE), physical activity was considerably lower in obese boys and girls, at $62-72 \%$ of the lean controls. In terms of simple correction for body weight, the observed fall in DLW-measured $\mathrm{PAEE} / \mathrm{kg}(31-38 \%)$ is only about half of the fall in this behavioural measure of activity as accelerometry-measured counts/kg (50-62\%).

Studies such as these show that not only is physical activity behaviour a different measure compared with PAEE derived from DLW measures as might be expected, but that in terms of the current gluttony $v$. sloth debate, 
DLW data, by far the major source of information informing the current debate, are inadequate as a measure of actual behavioural changes associated with weight gain. Direct measurements of PAEE by tri-axial accelerometry during 1 week in free-living overweight men and women in the Southern USA show that $95 \%$ of their active time is spent in low-intensity PAEE, suggesting a sedentary lifestyle. Importantly, the amount of free-living PAEE negatively correlated with body fatness to the extent that in ageand sex-adjusted multiple regressions, average and maximum weekday PAEE explained $29-32 \%$ of the variation in body fat ${ }^{(70)}$. Such information and that shown in Table 2 clearly indicate that physical activity behaviour is markedly reduced in the obese in line with common experience, with the latter study showing that such changes can contribute to obesity.

In the case of DLW studies limited to predominantly lean population groups, the difficulty of assessing the physiological implication of varying PAL values does not arise. There are several reports of DLW-determined values for PAL in lean population groups in non-industrialised societies living subsistence lives, who can be expected to expend high levels of PAEE: i.e. Gambian agriculturalists measured during harvesting season $(\mathrm{PAL}=2 \cdot 4)^{(71)}$ and Bolivian Aymara men measured during pre-harvest season $(\mathrm{PAL}=2 \cdot 0)^{(72)}$. One important study has investigated the Hadza, a population of hunter-gatherers in Northern Tanzania in terms of both DLW measures of EE and estimates of walking distance ${ }^{(73)}$. The men of this latter group walked on average $11.4 \mathrm{~km} / \mathrm{d}$, were lean (BMI $20 \cdot 3 \mathrm{~kg} / \mathrm{m}^{2}$ ) and exhibited mean PAL values of $2 \cdot 26$ ( $n$ 13; range $1.67-2.96$ ). In contrast, the women who were also lean (BMI $20 \cdot 2 \mathrm{~kg} / \mathrm{m}^{2}$ ), walked half the distance of the men $(5.8 \mathrm{~km} / \mathrm{d})$, with lower PAL (1.78; range 1.44-2.53). Also studies of lean UK subjects with high levels of leisure physical activity have been shown to have PAL values that are consistent with their activity ${ }^{(74)}$. For this group of healthy lean men (BMI 21.6 (SD 1.5) $\mathrm{kg} / \mathrm{m}^{2}$, age 38 (SD 9) years), with sedentary jobs but most of whom (seven out of nine) reported active leisure activities, the active men exhibited high PAL (mean $2 \cdot 12$; range 1.79-2.41) and for competitive runners in training, mean PAL was $2 \cdot 2$ (range $2 \cdot 02-2 \cdot 41$ ). Thus, the interpretation of DLW data on its own only becomes difficult when the subjects under study include a wide range of body weights. An example is a small DLW study of the Yakut (fourteen men and fourteen women), an indigenous high-latitude Siberian group, who rely on a mixture of subsistence activities, government wages and pensions, private-sector salaries and 'cottage' industries ${ }^{(75)}$. Subjects for the study were recruited to include both lean and overweight subjects, so that BMI ranged from 18.3 to $36.8 \mathrm{~kg} / \mathrm{m}^{2}$ for men and from 16.0 to $43.5 \mathrm{~kg} / \mathrm{m}^{2}$ for women. PAL values indicate only modest activity: i.e. for men, 1.68 (range $1 \cdot 34-2 \cdot 25$ ); and for women, 1.50 (range $1 \cdot 24-1 \cdot 91$ ). This suggests a relatively sedentary community. However, whether the sedentary nature of the group studied can be causally related to the presence of obesity in this community is difficult to judge from this small sample because although individual behaviour was assessed, any relationship of this with BMI was not reported. Although PAL tended to be higher for those with more traditional lifestyles, this relationship was only marginally significant.

\section{Changes in food intake in the UK}

As already indicated, although DLW measurements of EE are often used as a proxy measure for EI, there are limitations on what such data can tell us. In any case, population-based DLW data are themselves very limited. Nevertheless, knowledge of the likely range of DLW-derived PAL values allows expected rates of EE to be predicted for population groups on the basis of BMR calculated from weights and heights, and such values can be usefully compared with food EI measurements to provide a measure of their likely accuracy. For example, Table 3 shows such predicted EE/EI data for the adult current UK population; the median value is $10.7 \mathrm{MJ} / \mathrm{d}$ for

Table 2. Physical activity values of lean and obese 18-year-old boys and girls measured by doubly-labelled water (DLW) and accelerometry*

\begin{tabular}{|c|c|c|c|c|c|c|c|c|}
\hline & & \multirow[b]{2}{*}{$\begin{array}{l}\text { Body weight } \\
\text { (kg) }\end{array}$} & \multicolumn{3}{|c|}{ DLW data } & \multicolumn{3}{|c|}{ Accelerometry } \\
\hline & & & PAL† & PAEE $\ddagger(M J / d)$ & $\begin{array}{l}\text { PAEE adjusted } \\
\text { for body weight } \\
\text { (MJ/d per kg) }\end{array}$ & Total counts§ (per d) & $\begin{array}{c}\text { Counts } \\
\text { (per MJ PAEE) }\end{array}$ & $\begin{array}{l}\text { Counts } \\
\text { (per kg) }\end{array}$ \\
\hline$P$ for group & & & $<0.05$ & NS & & $<0.001$ & & \\
\hline \multirow[t]{2}{*}{ Boys } & Lean & 73.7 & 1.85 & $4 \cdot 6$ & 0.062 & 496 & 108 & $6 \cdot 7$ \\
\hline & Obese & 113 & $1 \cdot 7$ & 4.9 & 0.043 & 378 & 77 & $3 \cdot 3$ \\
\hline Girls & Obese & 102 & 1.63 & 3.5 & 0.034 & 339 & 97 & $3 \cdot 3$ \\
\hline Obese/lean & & & 0.94 & 1.03 & 0.62 & 0.63 & 0.62 & 0.38 \\
\hline
\end{tabular}

PAL, physical activity level; PAEE, physical activity energy expenditure; EE, energy expenditure.

* Data from Ekelund et al. ${ }^{(69)}$.

$\dagger P A L=E E / R M R$. EE measured over $15 \mathrm{~d}$ by DLW. RMR measured by indirect calorimetry.

$\ddagger$ PAEE $=0.9 \times \mathrm{EE}-\mathrm{RMR}$.

$\S$ Mean of $14 \mathrm{~d}$ value. 
Table 3. Food energy intakes necessary to match expected rates of energy expenditure of the current UK adult population

\begin{tabular}{|c|c|c|c|c|c|}
\hline \multirow[b]{2}{*}{ Population group } & \multirow[b]{2}{*}{ Weight* $^{*}(\mathrm{~kg})$} & \multirow[b]{2}{*}{$\mathrm{BMI}^{*} \dagger\left(\mathrm{kg} / \mathrm{m}^{2}\right)$} & \multicolumn{3}{|c|}{ Energy expenditure or energy intake $(\mathrm{MJ} / \mathrm{d}) \ddagger$} \\
\hline & & & $\begin{array}{l}\text { Less active } \\
(\mathrm{PAL}=1.49)\end{array}$ & $\begin{array}{l}\text { Population } \\
(\mathrm{PAL}=1.63)\end{array}$ & $\begin{array}{l}\text { More active } \\
(\mathrm{PAL}=1.78)\end{array}$ \\
\hline All men $16-75+$ years & 83 & $27 \cdot 0$ & 10.94 & 11.97 & 13.07 \\
\hline Range for age groups & $76-88$ & $23 \cdot 8-28 \cdot 7$ & $9.73-11.42$ & $10 \cdot 64-12 \cdot 50$ & $11 \cdot 62-13.65$ \\
\hline All women $16-75+$ years & 70 & $27 \cdot 0$ & 8.57 & $9 \cdot 37$ & $10 \cdot 23$ \\
\hline Range for age groups & $66-73$ & $24 \cdot 8-27 \cdot 3$ & $7 \cdot 63-8.91$ & $8 \cdot 35-9 \cdot 75$ & $9 \cdot 12-10 \cdot 64$ \\
\hline All adults $16-75+$ years & $76 \cdot 7$ & $27 \cdot 0$ & $9 \cdot 8$ & $10.7(2554)$ & $11 \cdot 7$ \\
\hline Range for age groups & $66-73$ & $24 \cdot 8-27 \cdot 3$ & $8 \cdot 7-10 \cdot 2$ & $9.5-11 \cdot 1$ & $10 \cdot 4-12 \cdot 1$ \\
\hline
\end{tabular}

PAL, physical activity level.

${ }^{*}$ From Health and Social Care Information Centre ${ }^{(2)}$

$\dagger$ At heights listed in Health and Social Care Information Centre ${ }^{(2)}$

¥Calculated from predicted BMR at population PAL values identified by the Scientific Advisory Committee on Nutrition ${ }^{(39)}$.

men and women combined, with the value for men $(11.97 \mathrm{MJ} / \mathrm{d}) 28 \%$ higher than for women $(9.37 \mathrm{MJ} / \mathrm{d})$ at the same BMI because of the higher height, body weight and BMR for men. Such predictions also allow modelling of the likely change in EI during the time that obesity has developed in the UK from 1955, the year after wartime rationing ended, to the present day. National statistics on weights and heights or BMI are scarce for that period but national data are available for men and women of varying age groups in 1943 (mean BMI $22.6 \mathrm{~kg} / \mathrm{m}^{2}$ ) and for male industrial employees for 1960 (BMI $24.2 \mathrm{~kg} / \mathrm{m}^{2}$ ) and for similar females for $1971\left(23.4 \mathrm{~kg} / \mathrm{m}^{2}\right)^{(3,4)}$, i.e. a mean BMI of $23.8 \mathrm{~kg} / \mathrm{m}^{2}$. On this basis a likely mean all-adult weight can be estimated from assumed mean heights and the corresponding mean BMR can be calculated. By assuming various initial PAL values, likely changes in food intake balancing predicted rates of EE between 1955 and 2010 can be calculated at least for the adult population, and Fig. 5 shows such modelling. Initial population PAL values have been chosen to range from $2 \cdot 0$ (very active), to the currently assumed value of 1.63 , calculated in each case for the likely minimum and maximum initial body weights. If the initial PAL were 1.82 the fall in PAEE to the current value would match the increasing BMR associated with the weight gain and predicted EI does not change. However, predicted food EI would increase for initial PAL values $<1.82$ or decrease for PAL values $>1.82$.

There are three types of estimate of food EI for the UK and information on all three is shown in Fig. 6. The FAO compiles data on national food balance sheets, converted to per capita overall food energy supply ${ }^{(76)}$. These data show little change between 1961 and 1990 (at about $13.4 \mathrm{MJ} / \mathrm{d}$ per capita) but after this intakes increase, by $5 \%$ to 2000 and by a further $2 \%$ to 2009 to reach $14.3 \mathrm{MJ} / \mathrm{d}$.

The second source of dietary EI data is the long-term record based on household food purchases that started in the UK in 1940. The data were recorded initially in the NFS although the sampling only became a complete cross-section of the British population from 1950. The NFS was changed in 2001 by merging with the Family
Expenditure Survey to form the Expenditure and Food Survey (EFS), with the food expenditure module published from 2002 as Family Food. The EFS is a 2-week diary record of all expenditure by each household member over the age of 7 years, i.e. 12196 individuals within 5263 UK households in 2010. The main feature of these records has been a steady decline in food EI. A recent 2010 report $^{\text {(77) }}$ stated: 'A reduction of 0.5 per cent in 2010 reaffirms the downward trend in energy intake. Energy intake was 1.2 per cent lower in 2010 than in 2007. On the basis of the analysis reported in 2010 the average energy intake per person from food and drink declined by 28 per cent between 1974 and 2010.' Exactly how this latter change is calculated is not clear in the report, but in any case these food records require careful examination. The reported per capita values (total purchases/number in household) involve several assumptions, including within-household share, so that demographic changes in household composition could influence the trend. However, a statistical analysis in the 1998 report $^{(78)}$ showed that between 1974 and 1998 the fall in recorded EI was apparent for men and women at most ages, although at a lower rate for the very young and old. The main difficulty in analysing long-term trends is that the basis of estimation of EI has evolved and changed over the years. Thus, confectionery, alcoholic drinks and soft drinks brought home were only included from 1992 and eating out was added for the first time in 1994, with reliable data available from 2001 within the EFS. Also in a recent Family Food report ${ }^{(77)}$, intakes recorded by the EFS are said to be more accurate than estimates of household purchases in the NFS because of an improved methodology including basing household food purchases on till receipts which is assumed to reduce under-reporting error. In addition, in Family Food reports up to 2008 an allowance of $10 \%$ was made for wastage. Because of this in the 2010 report, earlier NFS values, from 1974 to 2000, were corrected and scaled up (on average by $+8 \cdot 3 \%$ ). Fig. 6 shows the original unadjusted values from 1955, the first full year after post-war rationing ended in 1954, with step increases occurring with each of the two above-described 


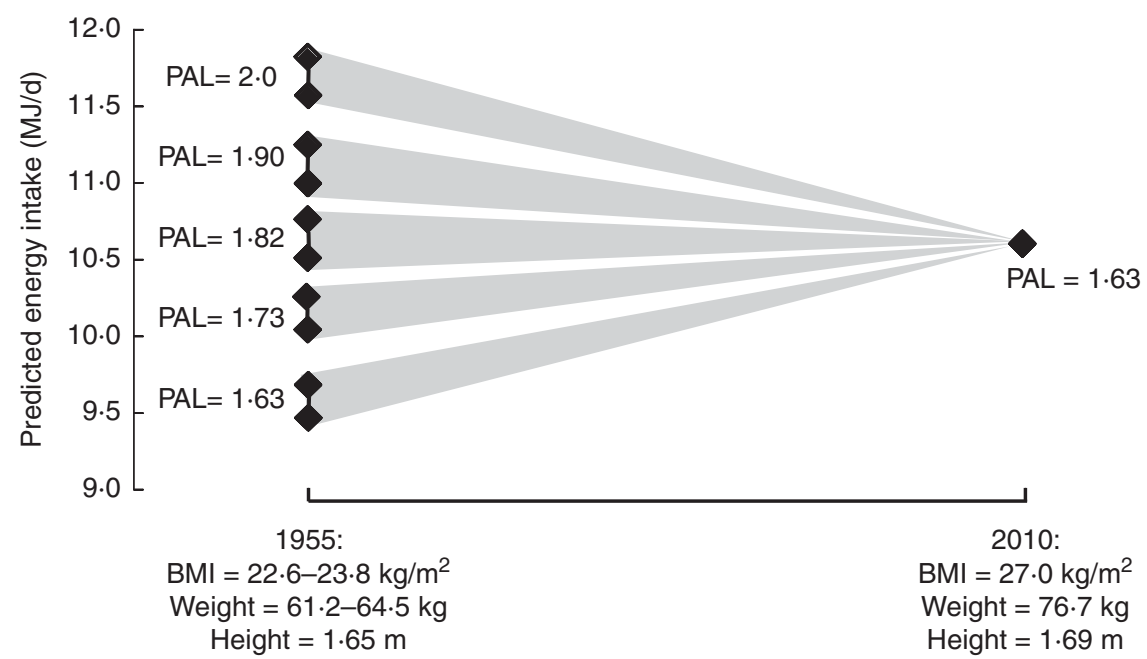

Fig. 5. Likely changes in food intake balancing various predicted rates of energy expenditure from 1955 to current 2010 assumed population values. Predicted rates of energy expenditure for 1955 are BMR $\times$ physical activity level (PAL), with the PAL values ranging from very active (2.0) to the currently assumed population value of 1.63 . BMR is predicted for adults (men and women) at the likely range of BMI values $\left(22.6\right.$ and $23.8 \mathrm{~kg} / \mathrm{m}^{2}$; see text), equivalent to weights of 61.2 and $64.5 \mathrm{~kg}$ at mean heights for men and women combined to be $1.65 \mathrm{~m}$. This latter value is $3.9 \mathrm{~cm}$ less than current values, assuming that over the 55 years there has been a steady increase in height at the rate reported for England between 1993 and $2010^{(2)}$. BMR is the mean of values calculated separately for men and women with the Henry prediction equations for weight and height ${ }^{(60)}$. The value for 2010 is the all-adult $16-75+$ years population value shown in Table 3 .

additions in 1992 and 1994, and with the change to the EFS in 2001. Fig. 6 shows two approaches to the adjustment of pre-2001 values to take into account the changes in methodology. Firstly, for both approaches the scaling applied to historical estimates of household purchases in the NFS from 1974 to 2000, to align with the more accurate intakes recorded by the EFS, has been applied to earlier values, from 1955 to 1973. Secondly, estimates of confectionery,

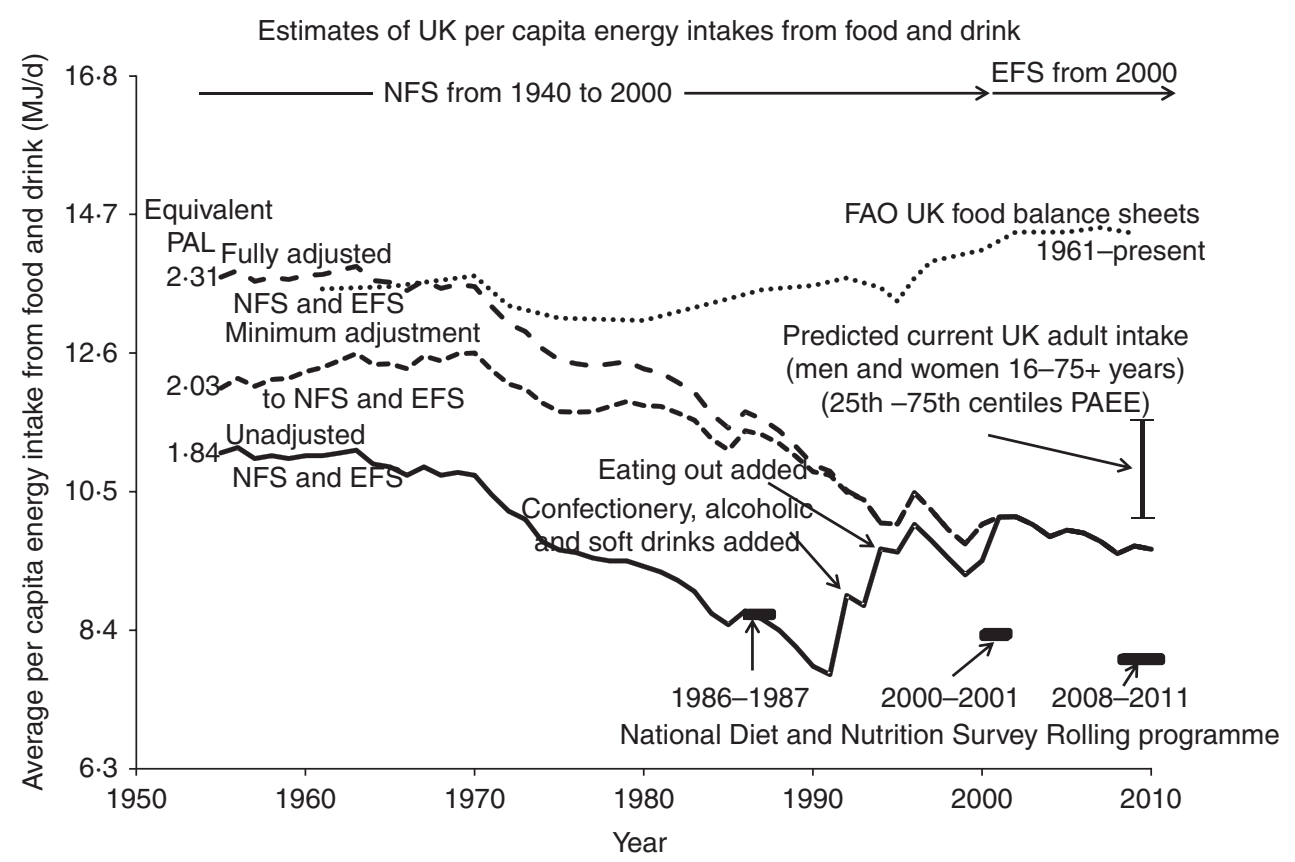

Fig. 6. Various estimates of food energy intakes for the UK since 1955 . Estimates of actual food consumption is reported by the $\mathrm{FAO}^{(76)}$ as per capita food energy supply estimated from national food balance sheets (supply, production, imports used for human consumption, after adjusting for food exports, livestock feeds, seed uses, losses during storage and transportation). Values have been reported since 1961. Household food purchases have been recorded in the National Food Survey (NFS) from 1940 to 2009 followed by the Expenditure and Food Survey (EFS) from 2001 ${ }^{(77)}$. The EFS is a 2-week diary record of all expenditure by each household member over the age of 7 years. Confectionery, alcoholic drinks and soft drinks brought home were only included from 1992 and eating out was added for the first time in 1994. The data are shown as unadjusted (i.e. as reported) and adjusted either minimally or more fully as described in the text so that the pre-1994 NFS data become comparable with those recorded in the EFS. Directly measured individual energy intakes are reported in the National Diet and Nutrition Survey for $1987-1988^{(79)}, 2000-2001^{(80)}$ and for $2008-2011^{(81)}$ when the survey has operated as a continuous rolling programme. PAL, physical activity level; PAEE, physical activity energy expenditure. 
etc., and eating out have been added to pre-1992 and -1994 values. To obtain a minimum initial estimate of the latter two additions, it has been assumed that the values increased linearly from zero in 1955 to an amount in 1991 for confectionery, etc. which is the mean of the values recorded in the NFS between 1992 to 2000, and to an amount in 1993 for eating out which was the mean of the recorded values for eating out as measured in the EFS (2001-2010), considered the best estimates. To obtain a most likely 'fully adjusted' estimate of the effect of these latter additions, it is assumed that initial purchases of confectionery, etc. in 1955 were half current estimates and increased linearly to the mean of the values recorded in the NFS between 1992 to 2000. For food consumption outside the home it is assumed that the extent of this was similar to current recorded values so that the mean value was added in all years before their measurement. On this basis, per capita EI in 1955 were $11.03 \mathrm{MJ} / \mathrm{d}$ unadjusted, $12.0 \mathrm{MJ} / \mathrm{d}$ minimally adjusted or $13.7 \mathrm{MJ} / \mathrm{d}$ fully adjusted. These 1955 intakes either remained flat or increased slowly until 1970 after which they decreased more markedly to the present. This indicates an overall fall from 1954 to 2010 by $1.46 \mathrm{MJ} / \mathrm{d}$ (13\%) in the unadjusted data, or by between $2.43 \mathrm{MJ} / \mathrm{d}$ to $4.1 \mathrm{MJ} / \mathrm{d}(20 \%$ to $30 \%$ ) after adjustment.

The third estimate is the measured EI reported in the NDNS. This is reported for $1987-1988^{(79)}, 2000-2001^{(80)}$ and for 2008-2011 ${ }^{(81)}$ when the survey has operated as a continuous rolling programme. There is a downward trend in the mean reported daily intakes for total energy for adult men and women for the three reported values: i.e. $8 \cdot 37,8 \cdot 29$ and $7 \cdot 86 \mathrm{MJ} / \mathrm{d}$. The earliest value closely corresponds to the unadjusted NFS values but the two subsequent values are very much lower than food supply values and lower than the food purchase values.

All of these values for estimated food EI shown in Fig. 6 can be compared with predicted current values of food EI from Table 3, shown in Fig. 6 as a range of all adult values from the less active 25 th centile (PAL $=1.43 ; 9.76 \mathrm{MJ} / \mathrm{d}$ ), to the more active 75 th centile $(\mathrm{PAL}=1 \cdot 78 ; 11.65 \mathrm{MJ} / \mathrm{d})$. Also on the basis of BMR values predicted from the higher of the two assumed 1955 body weights shown in Fig. 5 $(64.5 \mathrm{~kg})$ the $1955 \mathrm{EI}$ can be expressed as mean PAL values for matching rates of $\mathrm{EE}$ of adult men and women. Given that the household data relate to an average household individual (children, adults and the elderly, with a mean value of 2.32 individuals/household for 2010), the actual mean body weight will be slightly lower than the assumed value, the 1955 predicted PAL value equivalents of the intakes are slight underestimates while the 2010 predicted intakes are slight overestimates.

It is clear that there is a considerable mismatch between overall food supplies to the population and expected individual food energy consumption, i.e. food supply values currently markedly overestimate actual EI. The largest component of this mismatch is undoubtedly food wastage. This occurs before individual purchase, especially during packaging and supply to supermarkets, within supermarkets for limited shelf-life foods, and after purchase within the home. In the USA, the US Department of Agriculture assumes about one-third is wasted ${ }^{(82)}$. While various estimates of wastage in the UK are quoted, actual values are not known with any precision. One recent reliable estimate of household food and drink waste for the UK in 2009 ${ }^{(83)}$ was 8.3 (SD 0.3$)$ million tonnes per year, i.e. about $14 \%$ of the FAO food supply (about 60.4 million tonnes/ year) $^{(76)}$ (although the most recent information suggests that domestic food wastage is starting to fall in association with rising food prices and an economic squeeze $\left.{ }^{(84)}\right)$. Assuming similar food wastage before purchase during sorting, packaging and processing and through shelf life expiry at the retail level, then total UK wastage could be similar to that in the USA, and entirely account for the $>30 \%$ overestimate. More importantly in the present context, because of the changes in patterns of food processing, distribution, purchase and consumption since food balance sheet data became available in 1960, wastage has almost certainly increased, as in the $\mathrm{USA}^{(82)}$. This may well account for the rising UK food supply trend in recent decades. Indeed, the earliest food supply data for the 1960s may have been much less subject to wastage given that food purchase was largely from small local grocery shops and markets, consumption of ready meals was much less, and shelf life had not become an issue.

As for the declining food purchase EI trend shown in Fig. 6, if there is an increasing domestic wastage trend, in excess of the $10 \%$ already assumed in this survey, this would mean that the true trend was an even greater fall than indicated so that current EI estimates in the EFS would be lower than the values shown. In this case they would be too low. It may be that for subjects within the survey, wastage is much less than usual because of a behavioural change induced by participation in the survey and that the assumed $10 \%$ is a reasonable estimate. However, some under-reporting is to be expected and if this increased with time this could account for the declining trend. Family Food states: 'Under-reporting is a problem with all dietary surveys but is considered to be lower in the Family Food Module. Its focus on all expenditure with most food items collected from till receipts reduces the scope for under-reporting of household purchases. ${ }^{(85)}$ As it stands, the actual current recorded EFS intake value of $9.58 \mathrm{MJ} / \mathrm{d}$ is $2 \%(43 \mathrm{kcal} / \mathrm{d} ; 180 \mathrm{~kJ} / \mathrm{d}$ ) below the lower range (25th centile) all-adult population value of $9 \cdot 76 \mathrm{MJ} / \mathrm{d}$. However, as already indicated, this is not strictly a likefor-like comparison and because the per capita body weight for the EFS is lower than the assumed adult average, the EFS current recorded EI are not unreasonable. Certainly, the current EFS values are considerably higher than the NDNS values for adults which are physiologically unrealistically low, indicating considerable under-reporting in this survey. Because under-reporting of actual food 
intakes may be worse for the overweight or obese, especially for energy-dense food and drinks, EI trends as reported by the NDNS may be less reliable than the EFS values.

However, the fully adjusted 1955 values indicate intakes which, when applied to the adult population with body weights which can be assumed for that time, are equivalent to very high levels of physical activity: PAL values of 2.03 and 2.31 for the minimally or fully adjusted NFS intake, respectively, and 1.84 for the 1955 NFS intake without any adjustment. Is a population PAL value of 2 or more at all likely for the UK in 1955? While it is undeniable that lifestyles and occupations were quite different from those of the modern day, and while there are arguments in the literature that increasing leisure activity has more than compensated for changes in transport and occupational activities, there is simply not enough information to allow any sensible prediction of the magnitude of likely differences. As indicated above, few DLW studies have reported mean PAL values of 2 or more and such values represent the top $10 \%$ of observed PAL values within DLW datasets relating to current population groups. Thus, within the Scientific Advisory Committee on Nutrition (SACN) adult DLW dataset, of those within the normal body weight range ( $n 322$; mean $\mathrm{BMI}=22.7 \mathrm{~kg} / \mathrm{m}^{2}$, similar to the assumed 1955 value used in the calculations in Figs. 5 and 6), for whom PAL values were at or above the 90th centile value of 1.95 ( $n$ 35), the mean PAL was 2.08 (range 1.95-2.37). However, there is no information about the lifestyles of this very small subgroup. In the meta-analysis of all reported DLW studies, of which PAL values for industrialised countries are shown in Fig. $2^{(51)}$, of the studies showing study mean PAL values $\geq 2 \cdot 0$ ( $n$ 15; six women and nine men), three were from low or moderate developed societies, seven were overweight or obese, all were aged less than 65 years and most studies were very small (median $n$ 8). However, as indicated above, PAL values in excess of 2.0 were recorded in DLW studies of lean adult subjects in which either sedentary jobs were accompanied by high leisure activities ${ }^{(74)}$, or who exhibited high activity lifestyles (African ${ }^{(71)}$ or South American farmers ${ }^{(72)}$ ) or African hunter-gatherer men ${ }^{(73)}$ for whom walking long distances was recorded. Thus a population PAL for the UK in 1955 considerably higher than currently assumed values is certainly possible. It seems unlikely that food wastage was significant at that time and was inflating the unadjusted NFS estimate. The additional 2.64 MJ added within the full adjustment includes $0.91 \mathrm{MJ}$ for scaling, $1.16 \mathrm{MJ}$ for eating out and $0.55 \mathrm{MJ}$ for confectionery, soft drinks and alcohol, values which are not unreasonable although there is considerable uncertainty with each of these estimates, the extent of which is largely unknowable.

Can any firm conclusions be drawn from these data? Notwithstanding the considerable effort and expense put into the collection of the data, none is entirely satisfactory. However, assuming that the NFS/EFS trends are the best indicator for the UK, it would appear that food EI may have changed minimally before 1970 but has fallen steadily since, with a downward trend continuing in the most recent surveys. The data shown in Fig. 6 were compiled on the basis of reports up to 2010. The recently published 2011 Family Food report ${ }^{(84)}$ confirms the downward trend stating: 'There was a statistically significant reduction in energy intake from household food and drink in 2011 which is consistent with the longer term decline in energy intake from food and drink since the mid 1960s.' Whilst there are many potential inaccuracies in these data it is quite unlikely that they could be sufficiently large as to conceal an increase. Thus on the evidence of these data a simple gluttony without sloth explanation of the obesity epidemic is not supported.

\section{Direct evidence of physical activity-weight gain interactions}

Implicit to the Swinburn 'tipping point' model ${ }^{(18)}$ is that the reducing physical activity before the tipping point drives a matching fall in EI, i.e. appetite regulates energy balance when the diet is favourable (i.e. a low-fat, low-sugar diet as assumed for the pre 'tipping point' period). When the diet is unfavourable after fats and sugars increased to initiate the 'tipping point', appetite ceases to regulate energy balance, with weight gain acting as the 'mechanism' to restore energy balance through increased EE. Whilst this latter teleological description of weight gain is debatable, the role of appetite in first regulating and then failing to regulate energy balance in this way is not implausible. The difficulty is that current understanding of the interaction between physical activity, dietary composition, dietary EI and energy balance is by no means clear.

Within the Foresight programme, Wareham ${ }^{(45)}$ summarised his previous review of the evidence base relating physical activity and obesity prevention ${ }^{(86)}$ which had concluded that the ecological evidence for the increasing obesity prevalence to have occurred simultaneously with reductions in physical activity was rather limited. This reflected the limited validity of measures of total energy expenditure calculated from self-report data as used by the main source of information for the UK, The Health Survey for England (HSE) ${ }^{(2)}$. As with the household food survey methodology described above, the HSE questions on activity have changed over time, adding to the uncertainty in concluding that the reductions in physical activity indicated by proxy domain-specific measures (car ownership, household mechanisation, TV viewing, distance children walk per year and employment in physically demanding occupations) have resulted in actual overall reductions in the totality of physical activity. Clearly, studies involving objectively measured physical activity are likely to be more reliable although there are no such data relating to the whole period under discussion here. 
Thus, the objective data are either cross-sectional or prospective in terms of short time periods of a few years.

Cross-sectional studies clearly show that lower levels of physical activity are related to a higher risk of obesity in children, adolescents ${ }^{(87)}$ and adults ${ }^{(88)}$. However, crosssectional studies are clearly limited in identifying the causal direction of the relationship between physical activity and obesity, which is a real problem given the likelihood of behavioural changes occurring as a consequence of increasing fatness. In other words, bi-directional causality is highly likely. Prospective studies of physical activity and subsequent weight gain are less susceptible to misinterpretation, and the literature suggests that for adults, although there were mixed findings, overall the expected inverse association between physical activity and subsequent weight gain was found although the magnitude of the effect was small ${ }^{(86)}$. Similarly for children the expected relationship was found in some but by no means all studies, and, where found, the measures of association tended to be small. The most recent systematic review of prospective studies of objectively measured physical activity and obesity in children, adolescents and adults $^{(88)}$ showed that overall the observational studies show that physical activity is not strongly prospectively related with adiposity. For example, in one study of adults $^{(89)}$, although baseline PAEE (assessed by heart rate monitoring) did inversely predict change in body fat over 5 years in subjects below the median study age ( 54 years), albeit weakly (explaining $<1 \%$ of the variance in adiposity), for older subjects, who were on average weight stable, it predicted a higher body weight, fat mass and fat-free mass. It was suggested that physical activity attenuated weight loss and the development of sarcopenia. In a further analysis of this same study in which amount of time spent in the sedentary state rather than total PAEE was examined as a predictor of fat gain at follow up, no significant association was observed ${ }^{(90)}$. Indeed, the reverse association was observed with initial fat mass predicting sedentary time at follow up. It is the case that the subjects in the second study were a subset (50-57\%) of those in the first study and no attempt was made to separate the younger and older subjects. The authors make no comment about this other than to conclude that these two studies show that sedentary time and PAEE are differently associated with gain in fat mass and may be considered as separate entities in relation to health outcomes.

The studies included in these reviews examined PAEE with a variety of different methodologies, i.e. DLW, heart rate monitoring or accelerometry and, as indicated above (Table 2), they are not always comparable. Also, not all use direct measures of body fatness. Of those studies which used accelerometers in children, The Framingham Children's Study ${ }^{(91)}$ involved 8 years of activity monitoring by accelerometry from preschool to early adolescence in a small sample of 103 children and showed that those in the highest tertile of average daily activity had smaller gains in body fat assessed from five skinfold thickness measurements. Within a sample of prepubertal American Indian children aged 7.5 years, total activity measured by an accelerometer on $1 \mathrm{~d}$ predicted lower percentage fat measured 3 years later if they were normal weight at baseline ( $n$ 310) but not in those who were overweight at baseline ${ }^{(92)}$. The most recent studies involve continuous monitoring of movement with accelerometers, allowing detailed analysis of both total and intensity of activity throughout the day, and dual-energy X-ray absorptiometry measures of fatness. Two UK longitudinal studies have used these approaches: the Avon Longitudinal Study of Parents and Children (ALSPAC), a large birth cohort study that has reported on 12- to 14-year-old children ${ }^{(93-95)}$; and the smaller EarlyBird prospective cohort study of 5- to 10-year-olds ${ }^{(96,97)}$.

The initial ALSPAC study ${ }^{(93)}$ reported a cross-sectional analysis of 12 -year-olds ( $n$ 5500) showing that MVPA was very strongly negatively associated with fat mass so that the OR for obesity (the top decile for fat mass) for the top compared with bottom quintiles of minutes of MVPA was extremely low $(0.03$ for boys and 0.36 for girls). Subsequently ${ }^{(94)}$, 14-year-olds were included, allowing a prospective assessment of their physical activity at age 12 years with their subsequent adiposity at age 14 years. Using multilevel modelling of covariance of the repeated measures of both fat mass and physical activity (i.e. allowing fat mass at age 14 years to be controlled for the confounding effect of fat mass at age 12 years), fat mass at age 14 years was shown to be strongly inversely associated with physical activity at age 12 years for daily total and especially for MVPA in boys and girls. The authors comment that theirs is the only study that has measured both fat mass and physical activity with MVPA objectively in such a large cohort of adolescents ( $n 2418$ at each time point). Although the differences in fat mass between active and inactive children were small (10\%), the results indicate that an increase of $15 \mathrm{~min} / \mathrm{d}$ in MVPA at age 12 years is associated with a reduced fat mass of about $1 \mathrm{~kg}$ at 14 years. This means that for children who meet current health-related recommendations of $60 \mathrm{~min}$ of MVPA per $\mathrm{d}$, the observed relationship would predict $4.3 \mathrm{~kg}$ less fat mass at age 14 years than children who do no MVPA. The most recent report from this study ${ }^{(95)}$ involves an analysis in which fat mass is modelled as a continuous function of the profile of weekly physical activity rather than specific activity ranges. This indicates that the time spent in moderate and vigorous activity at 12 years of age has a negative contribution towards fat mass at 14 years while the time spent in sedentary and very light activity (i.e. slow walking and similar activities) has a positive contribution.

The EarlyBird study does not find the same predictive influence of physical activity on subsequent fatness observed in the ALSPAC children. In their initial report on 212 children aged $5-8$ years ${ }^{(96)}$, physical activity was 
measured annually over $7 \mathrm{~d}$ by accelerometry and the children were either categorised into more or less (than the median) active or by time spent meeting the government-recommended activity level of $>3$ MET. The change in fatness (skinfolds, waist circumference or BMI) over the 3 years was not different between the two activity groups and was not related to the number of minutes spent in activities $>3$ MET. What was shown, however, was that the higher activity was associated with an improved metabolic score (insulin resistance, TAG, cholesterol:HDL ratio and blood pressure). In a subsequent analysis of the cohort ( $n$ 202) between the ages of 7 and 10 years ${ }^{(97)}$ both total and MVPA and body fat (percentage body weight) were measured annually. Although cross-sectional analyses of either total physical activity or MVPA with fatness showed inverse relationships at each age and when time-lagged by $\pm 1,2$ and 3 years, when the direction of these relationships was examined in terms of the change in either physical activity or fatness as outcomes, regressed against the other variable as predictor, percentage body fat emerged as the significant negative predictor of the change in physical activity (especially MVPA), not the other way round. Although the significant relationships, when observed, were weak, with percentage body fat predicting $<5 \%$ of the variance in either total physical activity or MVPA, the authors were able to conclude that the inverse relationship between physical activity and percentage body fat is dominated by the impact of fatness on future activity rather than activity on future fatness.

It is not clear why the EarlyBird study did not find the clear influence of higher levels of physical activity on subsequent fatness observed in the much larger ALSPAC study given their similarity in methodologies. The statistical models used in the two studies are not entirely the same and while the former study involved mainly prepubertal boys and girls, puberty was well advanced for many of the ALSPAC cohort, with fat mass decreasing in boys and increasing in girls and with MVPA increasing faster in girls than boys. However, boys and girls exhibited similar influences of baseline total physical activity or MVPA on subsequent fatness. It remains to be seen whether subsequent measurements on these two cohorts continue to identify the different apparent relationships. The most recent ALSPAC study of the cohort up to the age of 15 years has involved dietary studies ${ }^{(98)}$. These have shown that dietary patterns characteristic of high dietary energy density, a greater percentage total energy from fat and low levels of fibre density, were positively associated with later fat mass. Thus, for this cohort at least both diet and physical activity appear to be involved in the development of fatness. Clearly, much more work is needed in this area.

\section{Conclusions}

This focus of the present review, i.e. an examination of evidence relevant to the gluttony $v$. sloth debate, has been limited to the post-Second World War UK population, at least as far as evidence about the food supply is concerned. The main conclusion is that obesity has developed against the background of a decline in food EI and by implication a decline in physical activity. Thus, this differs significantly from the two-phase 'energy flipping point' divided scenario proposed for the USA ${ }^{(18)}$. For the UK a post-Second World War 'eat more, gain weight' second phase is replaced by a 'move less-eat somewhat less but still too much' scenario. In other words, this is a partial failure of the strict appetite regulation which was surmised to match the decline in EI to a declining PAEE in the US pre-Second World War 'move less, stay lean' phase ${ }^{(18)}$. It might be argued that for the UK the 'flipping point' occurred when the level of EE fell below a threshold at which the appetite mechanism starts to fail. However, the extent to which the UK underwent a 'move less, stay lean' phase in the first half of the 20th century is difficult to judge because reliable EI or EE data are not available for this period. Also the food purchase EI data shown in Fig. 6 indicate that in 1955 when obesity was beginning in the UK, population activity levels were high. Thus a 'flipping point' scenario is highly unlikely.

The UK scenario proposed here in no way downgrades the importance of obesogenic dietary drivers, so that postwar changes in the UK food supply are undoubtedly part of the problem. The difficulty is in identifying how large this part is. From the perspective of a first-principle examination of behavioural influences on the two components of the energy balance equation, $\mathrm{EI}$ and $\mathrm{EE}$, it has been pointed out that EI (eating) is $100 \%$ behavioural but for EE, much less than half (PAEE) is behaviour ${ }^{(99)}$. Thus it might be thought reasonable to focus entirely on EI. However, such an analysis would ignore the interactive nature of these behaviours. On the one side, physiological control is exerted on eating through the appetite mechanism, the effectiveness of which may vary with overall PAEE and $\mathrm{EE}^{(100)}$. On the other side the existence of SPA, which appears to be phenotypically determined, exhibiting marked inter-individual variability, may account in some individuals for a large fraction of PAEE. Thus, it is by no means clear from first principles which behaviours should be the main focus in seeking to identify causality. What is clear from the evidence reviewed here is that low population levels of physical activity cannot be simply removed from the debate about causality.

The difficulty in accepting a decline in physical activity appears to flow from a misunderstanding of what the DLW database can and cannot reveal. It has revealed a near-complete description of the likely range of sustainable EE for individuals and small population groups and this has proved useful in exercises such as the prediction of population food energy requirements. However, the present review has shown that it is much less good at assessing physical activity behaviour especially within most current population groups which include a majority of 
overweight and obese individuals. For these groups the lack of any change in the distribution of PAL values or absolute rates of PAEE is almost certainly concealing marked behavioural changes in activities which are revealed by different methodologies such as accelerometry ${ }^{(68,69)}$, and are, in fact, easily identifiable if weightcorrected values of PAEE are used instead of PAL. The further development of such methodologies and their application in future DLW studies would markedly improve understanding. DLW data of EE can be used to reveal whether population-based food EI data are sensible and to model EI for specified EE, but their use as a test of the hypothesis that increases in the food supply are the dominant drivers of the weight gain in populations' is unconvincing.

The reason that the gluttony $v$. sloth debate is important is that while support for the moderation of gluttony is universal, support for moderating sloth (increasing exercise) has consistently been equivocal. It is certainly the case that physical activity intervention studies in children have generally failed to identify an influence on fatness, in that of the three studies in which physical activity was increased by the intervention only in one was a beneficial influence on fatness identified (see Jiménez-Pavon et $a l{ }^{\left({ }^{(8)}\right)}$. Although there is longstanding evidence that exercise can improve appetite control by several mechanisms, the efficacy of exercise as a means of weight reduction is regularly scrutinised ${ }^{(101)}$. Some of these doubts flow from the now well-documented fact that exercise as a means of weight reduction simply does not work for everyone - there is a continuum between responders and non-responders ${ }^{(102)}$. It is also the case that in many exercise intervention studies the magnitude of the energy imbalance expected from the increased exercise is less than in most EI restriction studies. Thus, in exercise intervention studies reviewed by Thomas et al. ${ }^{(103)}$ prescribed exercise interventions resulted in median energy deficits of only 0.98 (range $0.2-2.9$ ) $\mathrm{MJ} / \mathrm{d}$ compared with the $2 \mathrm{MJ} / \mathrm{d}$ deficit usually recommended in dietary restriction studies. Also, these authors concluded from their calculations of energy imbalance actually achieved (from body composition measurements) that in many cases EI had increased, reducing the potential for weight and fat loss.

Whatever the efficacy of increasing EE through exercise as a tool in weight management, it is clear that exercise delivers health benefits for both the general population $^{(104-107)}$ and in children ${ }^{(97)}$ in terms of improved well being and disease risk reduction. It can also reduce obesity risk especially in those with a high genetic susceptibility $^{(108)}$. Indeed, the most recent study of gene-lifestyle interactions has shown that the adverse influence of sedentary behaviour (TV watching) and beneficial influence of increasing leisure-time physical activity appear to have separate influences on the genotypic propensity for obesity $^{(109)}$. This indicates that public health efforts to prevent obesity and related cardiometabolic diseases should include efforts to both increase exercise levels and reduce sedentary behaviours, which would be of particular benefit to those who are more genetically predisposed to obesity. Even non-responders to an exercise-induced weight-loss regimen demonstrate decreased blood pressure, loss of abdominal fat and improved mood associated with improved aerobic fitness ${ }^{(110)}$. Within a large cohort (about 10 000) of dyslipidaemic veterans, increased fitness was as effective as statins in reducing mortality ${ }^{(111)}$. There are also nutritional advantages of maintaining a higher level of EE and balancing EI in terms of ensuring a healthy balanced diet. It is the case that nutrient requirements are defined in most cases on a body-weight basis so that as energy requirements and matching EI fall, the diet must become increasingly nutrient dense to meet nutrient requirements. This principle has been explored in relation to the adequacy of dietary protein intakes from typical UK omnivore and vegetarian diets for elderly men and women ${ }^{(112,113)}$. If these groups are sedentary, energy needs can become sufficiently low that significant risk of protein deficiency (intakes $<$ requirement) can be identified in terms of protein needs as currently defined, and this principle is likely to be the case for several other nutrients. Thus, as EE and matching EI increase it becomes easier to follow the healthy diet guidelines ensuring both macro- and micronutrient adequacy. In the UK there is clear government advice to increase physical activity ${ }^{(104)}$ but the reason why some individuals are physically active and others not is a complex question which remains poorly understood $^{(114)}$. At least one report ${ }^{(37)}$ found that young individuals would like to be active but are often constrained by external factors such as school policy or curricula, parental rules in relation to safety and convenience, and physical environmental factors. It is to be hoped that a legacy of the London Olympic Games is to improve the current low proportion of the population which meets such targets ${ }^{(2)}$, not least by reversing some of the declining trends in overall school sports activity ${ }^{(115)}$.

\section{Acknowledgements}

The present review was supported by a grant from the British Nutrition Foundation. The author thanks Jim Holding of the Department for Environment, Food and Rural Affairs for useful discussion about the NFS and EFS surveys and adjustments of the NFS as shown in Fig. 6, and staff at the British Nutrition Foundation for help with the literature search.

There are no conflicts of interest.

\section{References}

1. Lim SS, Flaxman AD, Andrews KG, et al. (2012) A comparative risk assessment of burden of disease and injury attributable to 67 risk factors and risk factor clusters in 21 regions, 
1990-2010: a systematic analysis for the Global Burden of Disease Study 2010. Lancet 380, 2224-2260.

2. Health and Social Care Information Centre (2012) Lifestyles Statistics. Statistics on obesity, physical activity and diet: England. http://www.ic.nhs.uk/statistics-and-data-collections/ health-and-lifestyles/obesity/statistics-on-obesity-physical-activity-and-diet-england-2012 (accessed 17 April 2012).

3. James WPT (1976) Research on Obesity: a Report by the DHSS/MRC Group. London: HM Stationery Office.

4. Khosla T \& Lowe CR (1968) Height and weight of British men. Lancet 291, 742-745.

5. Finucane MM, Stevens GA, Cowan MJ, et al. (2011) National, regional, and global trends in body-mass index since 1980: systematic analysis of health examination surveys and epidemiological studies with 960 country-years and 9.1 million participants. Lancet 377, 557-567.

6. Prospective Studies Collaboration, Whitlock G, Lewington S, et al. (2009) Body-mass index and cause-specific mortality in 900000 adults: collaborative analyses of 57 prospective studies. Lancet 373, 1083-1096.

7. Berrington de Gonzalez A, Hartge P, Cerhan JR, et al. (2010) Body-mass index and mortality among 1.46 million white adults. $N$ Engl J Med 363, 2211-2219.

8. Baumgartner RN, Stauber PM, Koehler KM, et al. (1996) Associations of fat and muscle masses with bone mineral in elderly men and women. Am J Clin Nutr 63, 365-372.

9. de Hollander EL, Bemelmans WJE, Boshuizen HC, et al. (2012) The association between waist circumference and risk of mortality considering body mass index in 65- to 74-year-olds: a meta-analysis of 29 cohorts involving more than 58000 elderly persons. Int J Epidemiol 41, 805-817.

10. Department of Business, Innovation and Skills (2012) Foresight Tackling Obesities: Future Choices. http://www.bis. gov.uk/foresight/our-work/projects/published-projects/ tackling-obesities (accessed September 2012).

11. Popkin BM (2005) Using research on the obesity pandemic as a guide to a unified vision of nutrition. Public Health Nutr 8, 724-729.

12. Bouchard C (2007) The biological predisposition to obesity: beyond the thrifty genotype scenario. Int $J$ Obesity 31, $1337-1339$

13. Loos RJF (2012) Genetic determinants of common obesity and their value in prediction. Best Pract Res Clin Endocrinol Metab 26, 211-226.

14. Li S, Zhao JH, Luan J, et al. (2010) Cumulative effects and predictive value of common obesity-susceptibility variants identified by genome-wide association studies. Am J Clin Nutr 91, 184-190.

15. Prentice AM, Hennig BJ \& Fulford AJ (2008) Evolutionary origins of the obesity epidemic: natural selection of thrifty genes or genetic drift following predation release? Int J Obes 32, 1607-1610.

16. Speakman JR (2008) Thrifty genes for obesity, an attractive but flawed idea, and an alternative perspective: the 'drifty' gene hypothesis. Int J Obes 32, 1611-1617.

17. Chaput J-P, Klingenberg L, Astrup A, et al. (2011) Modern sedentary activities promote overconsumption of food in our current obesogenic environment. Obes Rev 12, e12-e20.

18. Swinburn BA, Sacks G, Hall KD, et al. (2011) The global obesity pandemic: shaped by global drivers and local environments. Lancet 378, 804-814.

19. Rutter H (2011) Where next for obesity? Lancet $\mathbf{3 7 8}$, 746-747.

20. Lang T \& Rayner G (2007) Overcoming policy cacophony on obesity: an ecological public health framework for policymakers. Obes Rev 8, Suppl. 1, 165-181.
21. Prentice AM \& Jebb SA (1995) Obesity in Britain: gluttony or sloth? BMJ 311, 437-439.

22. Hill JO \& Peters JC (1998) Environmental contributions to the obesity epidemic. Science 280, 1371-1374.

23. Hill JO (2006) Understanding and addressing the epidemic of obesity: an energy balance perspective. Endocr Rev 27, $750-761$.

24. Bassett DR, Schneider PL \& Huntington GE (2004) Physical activity in an Old Order Amish community. Med Sci Sports Exerc 36, 79-85.

25. Ferro-Luzzi A \& Martino L (1996) Obesity and physical activity. In Ciba Foundation Symposium 201: The Origins and Consequences of Obesity, pp. 207-227 [DJ Chadwick and G Cardew, editors]. New York: John Wiley and Sons.

26. Anderssen N, Jacobs DR Jr, Sidney S, et al. (1996) Change and secular trends in physical activity patterns in young adults: a seven-year longitudinal follow-up in the Coronary Artery Risk Development in Young Adults Study (CARDIA). Am J Epidemiol 143, 351-362.

27. Church TS, Thomas DM, Tudor-Locke C, et al. (2011) Trends over 5 decades in U.S. occupation-related physical activity and their associations with obesity. PLOS ONE $\mathbf{6}$, e19657.

28. James WPT (2008) The fundamental drivers of the obesity epidemic. Obes Rev 9, Suppl. 1, 6-13.

29. Ng SW \& Popkin BM (2012) Time use and physical activity: a shift away from movement across the globe. Obes Rev $\mathbf{1 3}$ 659-680.

30. Hallal PC, Andersen LB, Bull FC, et al. (2012) Global physical activity levels: surveillance progress, pitfalls, and prospects. Lancet 380, 247-257.

31. Das P \& Horton R (2012) Rethinking our approach to physical activity. Lancet 380, 189-190.

32. Craig CL, Marshall AL, Sjostrom M, et al. (2003) International Physical Activity Questionnaire: 12-country reliability and validity. Med Sci Sports Exerc 35, 1381-1395.

33. Andersen RE, Crespo CJ, Bartlett SJ, et al. (1998) Relationship of physical activity and television watching with body weight and level of fatness among children: results from the Third National Health and Nutrition Examination Survey. JAMA 279, 938-942.

34. Niemi I \& Pääkkönen H (2002) Time Use Changes in Finland Through the 1990s, vol. 2. Helsinki: Statistics Finland.

35. Samdal O, Tynjala J, Roberts C, et al. (2007) Trends in vigorous physical activity and TV watching of adolescents from 1986 to 2002 in seven European countries. Eur J Public Health 17, 242-248.

36. Nelson MC, Neumark-Stzainer D, Hannan PJ, et al. (2006) Longitudinal and secular trends in physical activity and sedentary behavior during adolescence. Pediatrics 118, e1627-e1634.

37. Dollman J, Norton K \& Norton L (2005) Evidence for secular trends in children's physical activity behaviour. Br J Sports Med 39, 892-897.

38. Sigmundová D, Ansari WE, Sigmund E, et al. (2011) Secular trends: a ten-year comparison of the amount and type of physical activity and inactivity of random samples of adolescents in the Czech Republic. BMC Public Health 11, 731.

39. Scientific Advisory Committee on Nutrition (SACN) (2011) Dietary Reference Values for Energy. London: The Stationery Office.

40. Talbot LA, Fleg JL \& Metter EJ (2003) Secular trends in leisure-time physical activity in men and women across four decades. Prev Med 37, 52-60.

41. Hill JO, Wyatt HR, Reed GW, et al. (2003) Obesity and the environment: where do we go from here? Science 299, $853-855$. 
42. Hall KD, Sacks G, Chandramohan D, et al. (2011) Quantifying the effect of energy imbalance on bodyweight change. Lancet 378, 826-837.

43. Fox KR \& Hillsdon M (2007) Physical activity and obesity. Obes Rev 8, Suppl. 1, 115-121.

44. Jebb SA (2007) Dietary determinants of obesity. Obes Rev $\mathbf{8}$, Suppl. 1, 93-97.

45. Wareham N (2007) Physical activity and obesity prevention. Obes Rev 8, Suppl. 1, 109-114.

46. Cutler DM, Edwards EL \& Shapiro JM (2003) Why have Americans become more obese? J Econ Perspect 17, 93-118.

47. Bleich S, Cutler D \& Murray C et al. (2007) Why is the developed world obese? National Bureau of Economic Research, Working Paper 12954. http://www.nber.org/ papers/w12954 (accessed 10 August 2009).

48. Anonymous (2011) Urgently needed: a framework convention for obesity control. Lancet 378, 741.

49. Prentice AM, Black AE, Coward WA, et al. (1986) High levels of energy expenditure in obese women. $\mathrm{Br}$ Med J (Clin Res Ed) 292, 983-987.

50. Luke A, Dugas LR, Ebersole K, et al. (2009) Energy expenditure does not predict weight change in either Nigerian or African American women. Am J Clin Nutr 89, 169-176.

51. Dugas LR, Harders R, Merrill S, et al. (2011) Energy expenditure in adults living in developing compared with industrialized countries: a meta-analysis of doubly labelled water studies. Am J Clin Nutr 93, 427-441.

52. Westerterp KR \& Speakman JR (2008) Physical activity energy expenditure has not declined since the 1980s and matches energy expenditure of wild animals. Int $J$ Obes 32, 1256-1263.

53. Westerterp KR \& Plasqui G (2009) Physically active lifestyle does not decrease the risk of fattening. PLOS ONE $\mathbf{4}$, e4745.

54. Swinburn BA, Sacks G, Lo SK, et al. (2009) Estimating the changes in energy flux that characterize the rise in obesity prevalence. Am J Clin Nutr 89, 1723-1728.

55. Millward DJ (2010) Energy expenditure and the obesity epidemic. Am J Clin Nutr 91, 1801-1802.

56. Swinburn BA, Sacks G, Lo SK, et al. (2010) Reply to DJ Millward. Am J Clin Nutr 91, 1802-1803.

57. Institute of Medicine (2005) Dietary Reference Intakes for Energy, Carbohydrate, Fiber, Fat, Fatty Acids, Cholesterol, Protein, and Amino Acids. Washington, DC: National Academy Press.

58. Tooze JA, Schoeller DA, Subar AF, et al. (2007) Total daily energy expenditure among middle-aged men and women: the OPEN Study. Am J Clin Nutr 86, 382-387.

59. Moshfegh AJ, Rhodes DG, Baer DJ, et al. (2008) The US Department of Agriculture automated multiple-pass method reduces bias in the collection of energy intakes. Am J Clin Nutr 88, 324-332.

60. Henry CJ (2005) Basal metabolic rate studies in humans: measurement and development of new equations. Public Health Nutr 8, 1133-1152.

61. Scarborough P, Burg MR, Foster C, et al. (2011) Increased energy intake entirely accounts for increase in body weight in women but not in men in the UK between 1986 and 2000. Br J Nutr 105, 1399-1404.

62. Swinburn B, Sacks G \& Ravussin E (2009) Increased food energy supply is more than sufficient to explain the US epidemic of obesity. Am J Clin Nutr 90, 1453-1456.

63. Haggarty P, Valencia ME, McNeill G, et al. (1997) Energy expenditure during heavy work and its interaction with body weight. Br J Nutr 77, 359-373.

64. Zurlo F, Ferraro RT, Fontvielle AM, et al. (1992) Spontaneous physical activity and obesity: cross-sectional and longitudinal studies in Pima Indians. Am J Physiol 263, E296-E300.

65. Thomas DM, Martin CK, Heymsfield SB, et al. (2010) A simple model predicting individual weight change in humans. J Biol Dyn 5, 579-599.

66. Snitker S, Tataranni PA \& Ravussin E (2001) Spontaneous physical activity in a respiratory chamber is correlated to habitual physical activity. Int J Obes Relat Metab Disord 25, 1481-1486.

67. Prentice AM, Goldberg GR, Murgatroyd PR, et al. (1996) Physical activity and obesity: problems in correcting expenditure for body size. Int J Obes Relat Metab Disord 20, 688-691.

68. Spadano JL, Must A, Bandini LG, et al. (2003) Energy cost of physical activities in 12-y-old girls: MET values and the influence of body weight. Int J Obes 27, 1528-1533.

69. Ekelund U, Aman J, Yngve A, et al. (2002) Physical activity but not energy expenditure is reduced in obese adolescents: a case-control study. Am J Clin Nutr 76, 935-941.

70. Buchowski MS, Acra S, Majchrzak KM, et al. (2004) Patterns of physical activity in free-living adults in the Southern United States. Eur J Clin Nutr 58, 828-837.

71. Heini A, Minghelli G, Diaz E, et al. (1996) Free-living energy expenditure assessed by two different methods in Gambian men. Eur J Clin Nutr 50, 284-289.

72. Kashiwazaki H, Dejima Y, Orias-Rivera J, et al. (1995) Energy expenditure determined by the doubly labelled water method in Bolivian Aymara living in a high altitude agropastoral community. Am J Clin Nutr 62, 901-910.

73. Pontzer H, Raichlen DA, Wood BM, et al. (2012) Huntergatherer energetics and human obesity. PLOS ONE 7, e40503.

74. Davidson L, McNeill G, Haggarty P, et al. (1997) Free-living energy expenditure of adult men assessed by continuous heart-rate monitoring and doubly-labelled water. $\mathrm{Br} J \mathrm{Nutr}$ 78, 695-708.

75. Snodgrass JJ, Leonard WR, Tarskaia LA, et al. (2006) Total energy expenditure in the Yakut (Sakha) of Siberia as measured by the doubly labeled water method. Am J Clin Nutr 84, 798-806.

76. Food and Agriculture Organization (2012) FAOSTAT: FAO Statistical Database. Geneva: FAO. http://faostat3.fao.org/ home/index.html (accessed August 2012).

77. Department for Environment, Food and Rural Affairs (2011) Family Food 2010. York: Food Statistical Unit.

78. Department for Environment, Food and Rural Affairs (1999) National Food Survey Report 1998. Annual Report on Food Expenditure, Consumption and Nutrient Intakes. London: The Stationery Office.

79. Gregory J, Foster K, Tyler H, et al (1990) The Dietary and Nutritional Survey of British Adults. London: HM Stationery Office.

80. Henderson L, Gregory J \& Swan G (2002) The National Diet and Nutrition Survey: Adults Aged 19-64. London: HM Stationery Office.

81. Department of Health (2012) Statistical Press Notice: National Diet and Nutrition Survey: headline results from years 1, 2 and 3 combined (2008/09-2010/11). http://mediacentre.dh.gov.uk/2012/07/25/statistical-press-notice-national-diet-andnutrition-survey-headline-results-from-years-1-2-and-3-combined-200809-201011/ (accessed August 2012).

82. Hall KD, Guo J, Dore M, et al. (2009) The progressive increase of food waste in America and its environmental impact. PLOS ONE 4, e7940.

83. WRAP (2009) Household Food and Drink Waste in the UK. http://www.wrap.org.uk/content/new-estimates-householdfood-and-drink-waste-uk (accessed September 2012). 
84. Department for Environment, Food and Rural Affairs (2012) Family Food 2011. York: Food Statistical Unit.

85. Department for Environment, Food and Rural Affairs (2012) Food and Drink Purchases by UK Households in 2011 with Derived Energy and Nutrient Intakes. https://www.gov.uk/ government/uploads/system/uploads/attachment_data/file/ 187153/familyfood-statsnotice-13Dec12.pdf (accessed December 2012).

86. Wareham NJ, van Sluijs EM \& Ekelund U (2005) Physical activity and obesity prevention: a review of the current evidence. Proc Nutr Soc 64, 229-247.

87. Jiménez-Pavon D, Kelly J \& Reilly JJ (2009) Associations between objectively measured habitual physical activity and adiposity in children and adolescents: systematic review. Int J Pediatr Obes 26, 3-18.

88. Wilks DC, Besson H, Lindroos AK, et al. (2011) Objectively measured physical activity and obesity prevention in children, adolescents and adults: a systematic review of prospective studies. Obes Rev 12, e119-e129.

89. Ekelund U, Brage S, Franks PW, et al. (2005) Physical activity energy expenditure predicts changes in body composition in middle-aged healthy whites: effect modification by age. Am J Clin Nutr 81, 964-969.

90. Ekelund U, Brage S, Besson H, et al. (2008) Time spent being sedentary and weight gain in healthy adults: reverse or bidirectional causality? Am J Clin Nutr 88, 612-617.

91. Moore LL, Gao D, Bradlee ML, et al. (2003) Does early physical activity predict body fat change throughout childhood? Prev Med 37, 10-17.

92. Stevens J, Suchindran C, Ring K, et al. (2004) Physical activity as a predictor of body composition in American Indian children. Obes Res 12, 1974-1980.

93. Ness AR, Leary SD, Mattocks C, et al. (2007) Objectively measured physical activity and fat mass in a large cohort of children. PLoS Med 4, e97.

94. Riddoch CJ, Leary SD, Ness AR, et al. (2009) Prospective associations between objective measures of physical activity and fat mass in 12-14 year old children: the Avon Longitudinal Study of Parents and Children (ALSPAC). BMJ 339, b4544.

95. Augustin NH, Mattocks C, Cooper AR, et al. (2012) Modelling fat mass as a function of weekly physical activity profiles measured by Actigraph accelerometers. Physiol Meas 33, 1831-1839.

96. Metcalf BS, Voss LD, Hosking J, et al. (2008) Physical activity at the government-recommended level and obesity-related health outcomes: a longitudinal study (Early Bird 37). Arch Dis Child 93, 772-777.

97. Metcalf BS, Hosking J \& Jeffery AN (2011) Fatness leads to inactivity, but inactivity does not lead to fatness: a longitudinal study in children (EarlyBird 45). Arch Dis Child 96, 942-947.

98. Ambrosini GL, Emmett PM, Northstone K, et al. (2012) Identification of a dietary pattern prospectively associated with increased adiposity during childhood and adolescence. Int J Obes 36, 1299-1305.

99. Caudwell P, Gibbons C, Hopkins M, et al. (2011) The influence of physical activity on appetite control: an experimental system to understand the relationship between exerciseinduced energy expenditure and energy intake. Proc Nutr SOC 70, 171-180.
100. King N, Caudwell P, Hopkins M, et al. (2009) Dual-process action of exercise on appetite control: increase in orexigenic drive but improvement in meal-induced satiety. Am J Clin Nutr 90, 921-927.

101. Blundell J (2009) Exercise makes you fat - what's going on? Nutr Bull 34, 380-382.

102. King N, Hopkins M, Caudwell P, et al. (2007) Individual variability following 12 weeks of supervised exercise: identification and characterization of compensation for exercise induced weight loss. Int J Obes 32, 177-184.

103. Thomas DM, Bouchard C, Church T, et al. (2012) Why do individuals not lose more weight from an exercise intervention at a defined dose? An energy balance analysis. Obes Rev 13, 835-847.

104. Department of Health (2004) At least five a week: evidence on the impact of physical activity and its relationship to health A report from the Chief Medical Officer. http:// www.dh.gov.uk/en/Publicationsandstatistics/Publications/ PublicationsPolicyAndGuidance/DH_4080994 (accessed August 2012).

105. Ekelund U, Franks PW, Sharp S, et al. (2007) Increase in physical activity energy expenditure is associated with reduced metabolic risk independent of change in fatness and fitness: the MRC Ely Study. Diabetes Care 30, 2101-2106.

106. Wareham NJ, Brage S, Franks PW, et al (2004) Physical activity and insulin resistance. In Insulin Resistance: Insulin Action and its Disturbances in Disease, pp. 317-400 [S Kumar and S O'Rahilly, editors]. Chichester: John Wiley and Sons.

107. Kohl HK, Craig CL, Lambert EV, et al. (2012) The pandemic of physical inactivity: global action for public health. Lancet 380, 294-305.

108. Li S, Zhao JH, Luan J, et al. (2010) Physical activity attenuates the genetic predisposition to obesity in 20000 men and women from EPIC-Norfolk prospective population study. PLoS Med 7, e1000332.

109. Qi Q, Li Y, Chomistek AK, et al. (2012) Television watching, leisure time physical activity, and the genetic predisposition in relation to body mass index in women and men. Circulation 126, 1821-1827.

110. King NA, Hopkins M, Caudwell P, et al. (2009) Beneficial effects of exercise: shifting the focus from body weight to other markers of health. BrJ Sports Med 43, 924-927.

111. Kokkinos PF, Faselis C, Myers J, et al. (2012) Interactive effects of fitness and statin treatment on mortality risk in veterans with dyslipidaemia: a cohort study. Lancet $\mathbf{3 8 1}$, 394-399.

112. Millward DJ \& Jackson AA (2004) Protein:energy ratios of current diets in developed and developing countries compared with a safe protein:energy ratio: implications for recommended protein and amino acid intakes. Public Health Nutr 7, 387-405.

113. World Health Organization (2007) Protein and Amino Acid Requirements in Human Nutrition. Report of a Joint WHO/ FAO/UNU Expert Consultation. World Health Organization Technical Report Series no. 935. Geneva: WHO.

114. Bauman AE, Reis RS, Sallis JS, et al. (2012) Correlates of physical activity: why are some people physically active and others not? Lancet 380, 258-271.

115. Vasagar J (2012) Is school sport in crisis? http://www. guardian.co.uk/education/2012/feb/07/is-school-sport-incrisis (accessed 3 September 2012). 